Article

\title{
Non-Isothermal Gas-Based Direct Reduction Behavior of High Chromium Vanadium-Titanium Magnetite Pellets and the Melting Separation of Metallized Pellets
}

\author{
Jue Tang *, Man-Sheng Chu *, Zi-Wei Ying, Feng Li, Cong Feng and Zheng-Gen Liu \\ School of Metallurgy, Northeastern University, Shenyang 110819, China; yingzw@smm.neu.edu.cn (Z.-W.Y.); \\ mingfeng0223@163.com (F.L.); fengcong21@126.com (C.F.); neufarhill@126.com (Z.-G.L.) \\ * Correspondence: juetang@126.com (J.T); chums@smm.neu.edu.cn (M.-S.C.); \\ Tel./Fax: +86-24-8368-4959 (J.T. \& M.-S.C.)
}

Academic Editors: Jordi Sort Viñas and Evangelos Hristoforou

Received: 14 March 2017; Accepted: 20 April 2017; Published: 26 April 2017

\begin{abstract}
The non-isothermal reduction behavior of high chromium vanadium-titanium magnetite (HCVTM) pellets by gas mixtures was investigated using different heating rates $(4,8$, and $12 \mathrm{~K} / \mathrm{min})$ and varied gas compositions $\left(\mathrm{H}_{2} / \mathrm{CO}=2 / 5, \mathrm{H}_{2} / \mathrm{CO}=1 / 1\right.$, and $\mathrm{H}_{2} / \mathrm{CO}=5 / 2$ volume ratios); the pellets were then used for melting separation. It was observed that the temperature corresponding to the maximum reduction ratio increased with the increasing heating rate. The HCVTM pellets reached the same final reduction ratio under a given reducing gas composition, although the heating rates were different. Under the same heating rate, the gas mixture with more $\mathrm{H}_{2}$ was conducive for obtaining a higher reduction ratio. The phase transformations during the non-isothermal reduction were ordered as follows: $\mathrm{Fe}_{2} \mathrm{O}_{3} \rightarrow \mathrm{Fe}_{3} \mathrm{O}_{4} \rightarrow \mathrm{FeO} \rightarrow \mathrm{Fe} ; \mathrm{Fe}_{9} \mathrm{TiO}_{15}+\mathrm{Fe}_{2} \mathrm{Ti}_{3} \mathrm{O}_{9} \rightarrow \mathrm{Fe}_{2.75} \mathrm{Ti}_{0.25} \mathrm{O}_{4} \rightarrow \mathrm{FeTiO}_{3} \rightarrow \mathrm{TiO}_{2}$; $\mathrm{V}_{1.7} \mathrm{Cr}_{0.3} \mathrm{O}_{3} \rightarrow \mathrm{V}_{2} \mathrm{O}_{3} \rightarrow \mathrm{Fe}_{2} \mathrm{VO}_{4} ; \mathrm{Fe}_{1.2} \mathrm{Cr}_{0.8} \mathrm{O}_{3} \rightarrow \mathrm{Cr}_{2} \mathrm{O}_{3} \rightarrow \mathrm{FeCr}_{2} \mathrm{O}_{4}$. The non-isothermal reduction kinetic model was established based on the unreacted core model with multiple reaction interfaces. The correlation coefficients were greater than 0.99 , revealing that this kinetic model could properly describe the non-isothermal reduction of the HCVTM pellets by gas mixtures. Iron containing V and $\mathrm{Cr}$ along with the Ti-rich slag was obtained through the melting separation of the metallized HCVTM pellets. The mass fractions and recovery rates of $\mathrm{Fe}, \mathrm{V}$, and $\mathrm{Cr}$ in the iron were $93.87 \%$ and $99.45 \%$, $0.91 \%$ and $98.83 \%$, and $0.72 \%$ and $95.02 \%$, respectively. The mass fraction and recovery rate of $\mathrm{TiO}_{2}$ in the slag were $38.12 \%$ and $95.08 \%$, respectively.
\end{abstract}

Keywords: high chromium vanadium-titanium magnetite; pellet; non-isothermal gas-based reduction; kinetics; melting separation

\section{Introduction}

High chromium vanadium-titanium magnetite (HCVTM) is a typically complex polymetallic iron ore resource with abundant reserves in China. It is mainly deposited around the Panzhihua-Xichang (Panxi) area in the Sichuan province and has a high comprehensive utilization value due to the significant reserves of $\mathrm{Fe}, \mathrm{V}, \mathrm{Ti}$, and $\mathrm{Cr}$ [1-3] in the ore. Currently, the main disposal method for this special iron ore is a blast furnace-converter process. However, the utilization rates of the valuable components $(\mathrm{Fe}, \mathrm{V}, \mathrm{Ti}$, and $\mathrm{Cr})$ are low, and the process results in serious environment pollution such as the use of a large quantity of solid reducing agent, the freely stacked Ti-bearing slag, and the leaching of toxic elements from the slag stock [4-6].

Some direct reduction processes have been attempted and adopted to utilize vanadium-titanium magnetite (VTM) or HCVTM [7-9]. Among these processes, one promising choice is the gas-based 
direct reduction process with the advantages of clean production, low carbon consumption, and a fast reaction rate [10]. Meanwhile, the Ti-bearing slag cannot be polluted by the gaseous reducing agent without ash, which is good for obtaining the Ti-bearing slag with high activity and grade leading to the smooth subsequent extraction of Ti from the slag. Several experiments have been conducted, and the mechanisms from different aspects have been studied, such as the gas-based reduction test, the reduction degree change rule, the reduction kinetics, phase transformations, and microstructure changes [11-16]. Zhang conducted fundamental research on gas-based reductions using Indonesian vanadium titanium ironsand and found that the conditions required for the pellets to achieve a metallization ratio of $90 \%$ were due to the high temperature, reduction potential, and hydrogen content [17]. In Li's work [18], the isothermal reduction kinetics of VTM pellets under $\mathrm{H}_{2}, \mathrm{CO}$, and $\mathrm{H}_{2}$-CO was investigated; it was shown that the pellets with small diameters and high porosities had good reducibility and that the restrictive step of the reduction process varies with the $\mathrm{H}_{2}$ content in the gas. Zhang et al. [19] reduced the VTM pellets with $\mathrm{H}_{2}-\mathrm{CO}-\mathrm{N}_{2}$ gas mixtures at 1173-1473 K, and the reaction was accelerated by increasing the $\mathrm{H}_{2}$ content, while the sticking was weakened. The isothermal reduction mechanisms of the titanomagnetite with pure $\mathrm{H}_{2}$ have been investigated by Sun et al. [8]. According to their research, the interfacial reaction was the main rate-controlling step during the entire reduction. Park et al. $[9,20]$ noted that the transformations of the Ti-bearing phases in the VTM during the $\mathrm{CO}$ reduction were listed as: $\mathrm{Fe}_{3-x} \mathrm{Ti}_{x} \mathrm{O}_{4} \rightarrow$ "FeO" $+\mathrm{Fe}+\left(\mathrm{Fe}_{3-x-\delta} \mathrm{Ti}_{x-\delta} \mathrm{O}_{4}\right) \rightarrow \mathrm{Fe}+$ $\left(\mathrm{Fe}_{3-x-\delta} \mathrm{Ti}_{x-\delta} \mathrm{O}_{4}\right) \rightarrow \mathrm{Fe}+\mathrm{Fe}_{2} \mathrm{TiO}_{4} \rightarrow \mathrm{Fe}+\mathrm{FeTiO}_{3} \rightarrow \mathrm{Fe}+\mathrm{TiO}_{2} \rightarrow \mathrm{Fe}+\mathrm{Ti}_{3} \mathrm{O}_{5} \rightarrow \mathrm{Fe}+\mathrm{FeTi}_{2} \mathrm{O}_{3}$.

Based on the above findings, there were no detailed studies concerning the gas-based reduction of HCVTM pellets, especially for non-isothermal reductions. The investigations of the kinetic mechanisms primarily focused on the rough judgments about the restrictive step of the reduction and lacked a detailed model to describe the gas-based reduction of VTM or HCVTM pellets. Additionally, the transformations of the phases containing $\mathrm{V}$ or $\mathrm{Cr}$ were not discussed in the early works. On the other hand, the application of the reduced pellets has also not been reported on in the previous literature. Thus, in this work, non-isothermal reduction experiments with HCVTM pellets in $\mathrm{H}_{2}-\mathrm{CO}-\mathrm{CO}_{2}$ gas mixtures were performed. Meanwhile, the reduction behavior and kinetics were studied systematically, and the metallized pellets were applied for melting separation.

\section{Materials and Methods}

\subsection{Raw Materials}

The HCVTM used in the present research was supplied by Jianlong Steel in Shuangyashan, China. The chemical composition of HCVTM and bentonite are listed in Table 1. The particle size was investigated using a MASTERSIZER2000 laser particle size analyzer (Malvern Instruments, Malvern, UK), seen in Figure 1. It was clear that the volume percent of the particle size less than $0.074 \mathrm{~mm}$ was only $29.98 \%$, which was not suitable for pelletizing. Therefore, the raw HCVTM was ground for the subsequent pelletizing test.

Table 1. Chemical composition of high chromium vanadium-titanium magnetite (HCVTM) and bentonite (wt \%).

\begin{tabular}{ccccccccccccc}
\hline Item & $\mathrm{TFe}$ & $\mathrm{V}_{\mathbf{2}} \mathrm{O}_{5}$ & $\mathrm{Cr}_{2} \mathrm{O}_{3}$ & $\mathrm{TiO}_{2}$ & $\mathrm{Al}_{2} \mathrm{O}_{3}$ & $\mathrm{SiO}_{2}$ & $\mathbf{M g O}$ & $\mathrm{CaO}$ & $\mathbf{S}$ & $\mathbf{P}$ & $\mathbf{N a}_{2} \mathrm{O}$ & $\mathbf{K}_{2} \mathbf{O}$ \\
\hline HCVTM & 62.12 & 0.95 & 0.61 & 5.05 & 3.18 & 2.12 & 0.92 & 0.22 & 0.04 & 0.01 & - & - \\
Bentonite & - & - & - & - & $14 . .47$ & 67.45 & 4.61 & 2.47 & - & - & 1.68 & 1.19 \\
\hline
\end{tabular}




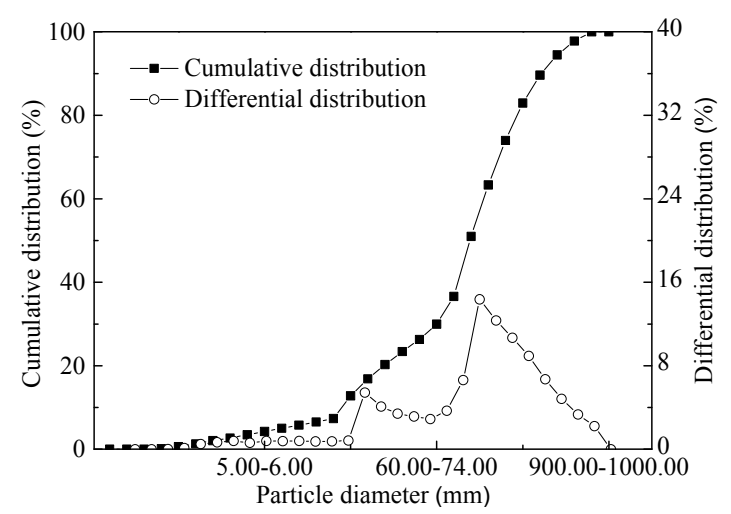

Figure 1. Particle size distribution of raw HCVTM concentrate.

\subsection{Experimental Procedure}

Based on the previously discussed background, a novel process of gas-based reduction followed by melting separation for the disposal of HVCTM was proposed. The outline process chart is presented in Figure 2 and contains three key steps: (1) The HCVTM together with the bentonite was used for pelletizing, and the oxidized pellets were obtained through oxidation roasting. (2) The oxidized pellets were reduced in the gas-based shaft furnace (designed by our team). (3) The metallized pellets were used for melting separation. Finally, the slag bearing $\mathrm{Ti}$ and the iron containing $\mathrm{V}$ and $\mathrm{Cr}$ were obtained. In the present work, the non-isothermal gas-based direct reduction behavior of the HCVTM pellets and the melting separation of the metallized pellets were investigated.

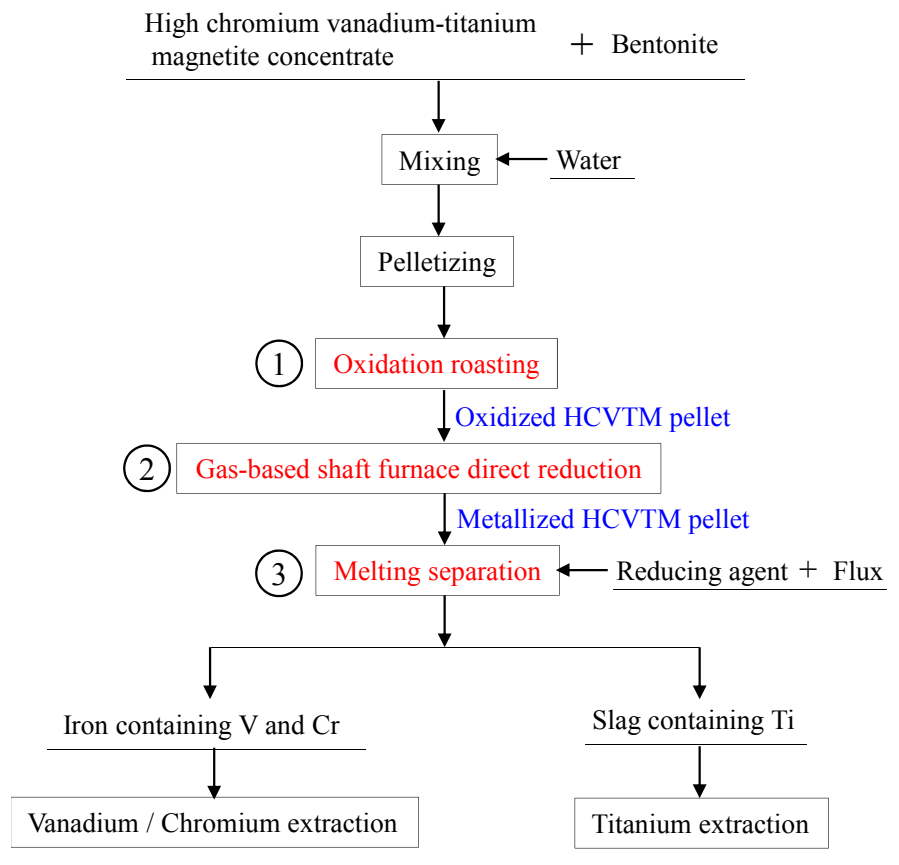

Figure 2. The outline process chart of the novel process for disposing of HVCTM.

\subsubsection{Pelletizing and Oxidizing of HCVTM}

The pelletizing and oxidizing process of HCVTM is shown in Figure 3. Due to the big particle size of the raw HCVTM concentrate, it was handled by a laboratory wet grinder (Yunhao Mining and Metallurgy Equipment, Nanchang, China). The grinding time was controlled to approximately $15 \mathrm{~min}$ to assure the proper particle size, and the size distribution is reported in Figure 4 . Then the ground HCVTM concentrate together with the bentonite was mixed for pelletizing. The addition 
of bentonite was $1.0 \mathrm{wt} \%$. Green pellets were prepared using a laboratory balling disc (Danxing Machinery Equipment, Zhengzhou, China) with a diameter of $1000 \mathrm{~mm}$, an edge height of $200 \mathrm{~mm}$, a tilting angle of $45^{\circ}$, and a rotational speed of $18 \mathrm{rpm}$. Then the green pellets were dried for $5 \mathrm{~h}$ at $378 \mathrm{~K}$ in air using a drying oven (Shenguang Instrument Equipment, Shaoxing, China). Afterwards the pellets with diameters of 10-12.5 mm were screened and roasted in air using a muffle furnace (Weite Furnace, Luoyang, China). The oxidized HCVTM pellets (seen in Figure 5) were roasted for $20 \mathrm{~min}$ at $1573 \mathrm{~K}$ and were applied for non-isothermal gas-based reduction.

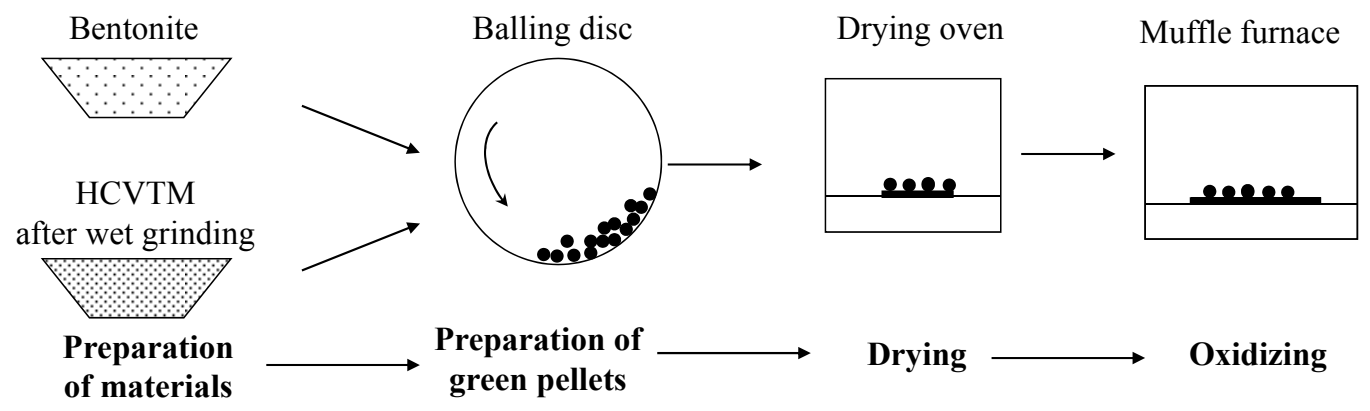

Figure 3. Pelletizing and Oxidizing process of HCVTM.

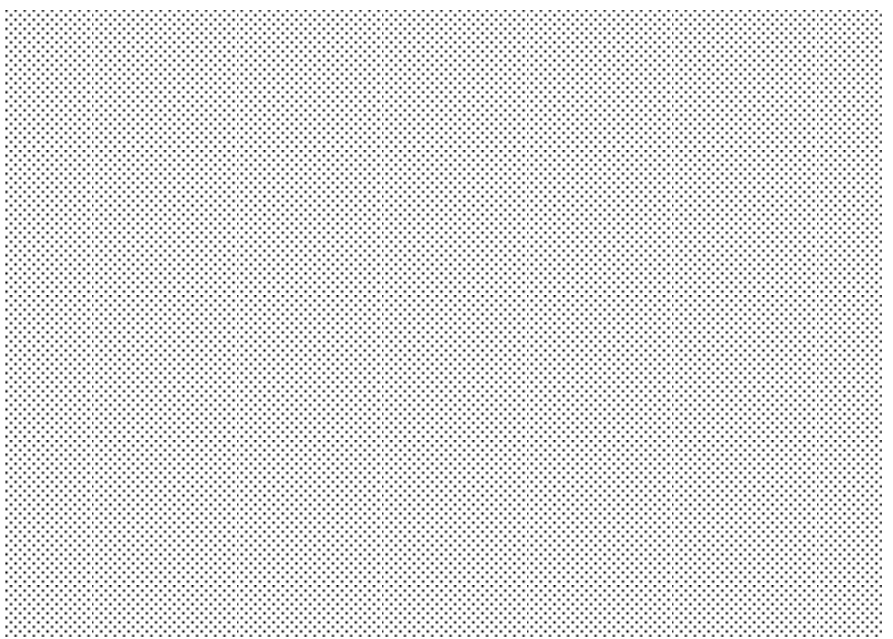

Figure 4. Particle size distribution of HCVTM concentrate after grinding for $15 \mathrm{~min}$.

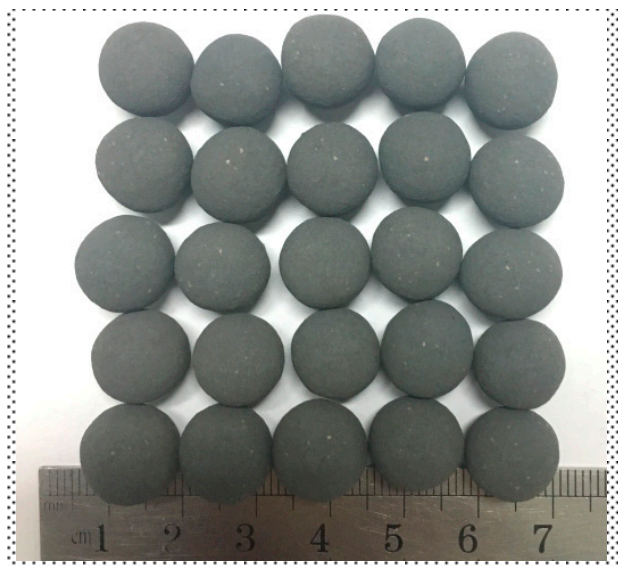

Figure 5. Picture of oxidized HCVTM pellets. 


\subsubsection{Gas-Based Shaft Furnace Direct Reduction of Oxidized HCVTM Pellets}

The non-isothermal gas-based reduction was performed in a laboratory gas-based shaft furnace (designed by our team), as shown in Figure 6. Twenty oxidized HCVTM pellets with diameters of $12 \pm 0.50 \mathrm{~mm}$ were placed into the crucible and moved to the effective temperature zone. Before the reduction, a $\mathrm{N}_{2}$ flow was applied with a rate of $4 \mathrm{~L} / \mathrm{min}$ for several minutes to remove air from the furnace. Then, by adjusting the temperature controller, the heating rate $\beta(\mathrm{K} / \mathrm{min})$ was set, and the $\mathrm{N}_{2}$ flow was replaced by the $\mathrm{H}_{2}-\mathrm{CO}-\mathrm{CO}_{2}$ gas mixture with the same flow rate of $4 \mathrm{~L} / \mathrm{min}$. Then, the reduction process began, and the weight loss was recorded by an electronic balance (Shengke Instrument Equipment, Shanghai, China) every $30 \mathrm{~s}$. When there was no longer a change in the weight, the process was considered complete. After the reduction process, the crucible along with the pellet was removed from the furnace and was quickly cooled under an Ar flow. The reduction ratio was evaluated as the fraction of oxygen removed from the oxidized pellets. However, the oxides containing $\mathrm{Ti}, \mathrm{V}$, and $\mathrm{Cr}$ almost could not be reduced under the experimental temperature and atmosphere conditions. Therefore, the reduction ratio was approximately considered as the mass percentage of oxygen removed from the iron oxides and was calculated by Equation (1):

$$
R=\left[\frac{0.11 w_{1}}{0.43 w_{2}}+\frac{m_{0}-m_{t}}{0.43 m_{0} w_{2}} \times 100\right] \times 100 \%
$$

where, $w_{1}$ is the content of $\mathrm{FeO}$ in the oxidized HCVTM pellets, $\%$; $w_{2}$ is the content of total $\mathrm{Fe}$ in the oxidized HCVTM pellets, $\% ; m_{0}$ is the initial mass of oxidized HCVTM pellets after removal of moisture, g; $m_{t}$ is the mass of the pellets after reducing each time $t, \mathrm{~g}$; and 0.11 and 0.43 are the conversion coefficients.

Three heating rates $(4,8$, and $12 \mathrm{~K} / \mathrm{min})$ and gas compositions $\left(\mathrm{H}_{2} / \mathrm{CO}=2 / 5, \mathrm{H}_{2} / \mathrm{CO}=1 / 1\right.$, and $\mathrm{H}_{2} / \mathrm{CO}=5 / 2$ volume ratios) were considered in the non-isothermal gas-based direct reduction. The volume content of the $\mathrm{CO}_{2}$ in the reducing gas was kept constant at $5 \%$.

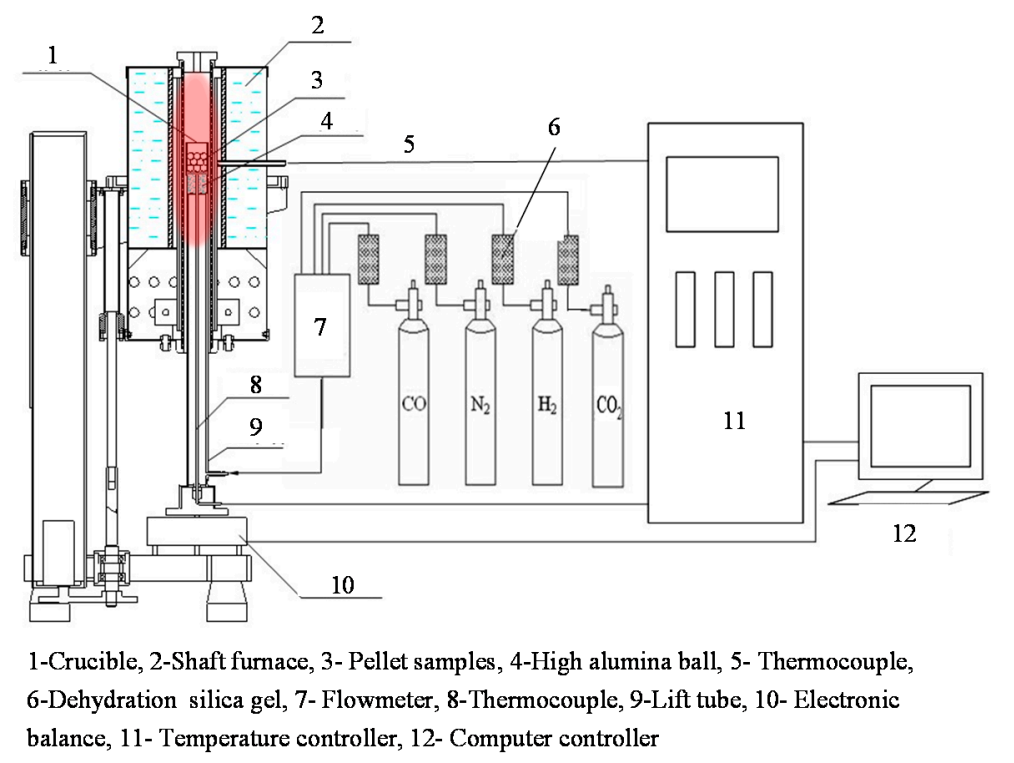

Figure 6. Schematic of the laboratory gas-based shaft furnace.

\subsubsection{Melting Separation of the Metallized HCVTM Pellets}

The melting separation proceeded in a medium frequency induction furnace (XZ-40B) (Kechuang Furnace, Zhengzhou, China), with a schematic given in Figure 7. The temperature was measured using an infrared thermometer (DT-8869h) (Huashengchang Instrument, Shenzhen, China) with a measurement range of $223-2473 \mathrm{~K}$ and an accuracy of $0.1 \mathrm{~K}$. The metallized HCVTM pellets were 
crushed to below $1 \mathrm{~mm}$ in diameter. Then, the powder samples, reducing agent, and flux were loaded into a high purity graphite crucible (Metallurgy Graphite Material, Shenyang, China) after weighing and were mixed homogeneously. Next, the crucible was placed into the effective temperature zone and heated to a high temperature to realize the separation between the iron and the slag. The temperature and time for the melting separation was controlled at $1923 \mathrm{~K}$ for $40 \mathrm{~min}$. After the melting separation was complete, the sample was rapidly cooled under an Ar flow.

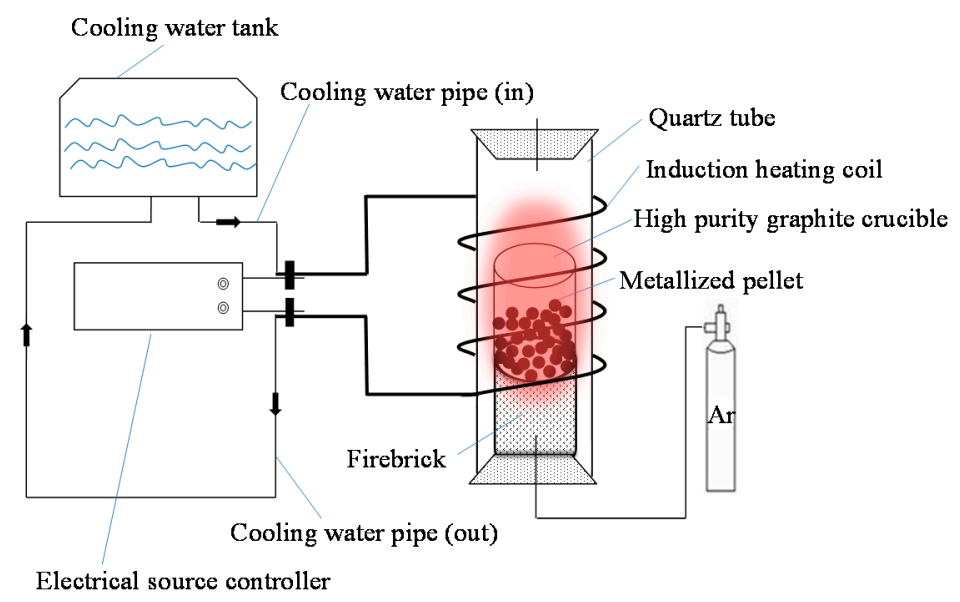

Figure 7. Schematic of the medium frequency induction furnace.

The phase composition and microstructure of the reduced samples were investigated using XRD (X-ray Diffraction) (Siemens, Berlin, Germany) and SEM-EDS (Scanning Electron Microscopy-Energy Dispersive Spectrometer) (Zeiss, Oberkochen, Germany) analysis, respectively. The chemical composition of the iron and separated slag were analyzed by ICP-OES (Inductively Coupled Plasma Optical Emission Spectrometry) (Perkin Elmer, Waltham, MA, USA).

\section{Results and Discussion}

\subsection{Properties of Oxidized HCVTM Pellets}

The chemical compositions of the oxidized HCVTM pellets are listed in Table 2. XRD analysis was performed to determine the main phases containing $\mathrm{Fe}, \mathrm{Ti}, \mathrm{V}$, and $\mathrm{Cr}$, as shown in Figure 8 . The results indicated that hematite was the main phase, and Ti was present in the forms of $\mathrm{Fe}_{9} \mathrm{TiO}_{15}$ (TTH) and $\mathrm{Fe}_{2} \mathrm{Ti}_{3} \mathrm{O}_{9}$. $\mathrm{V}$ and $\mathrm{Cr}$ generated their own solid solutions of $\mathrm{V}_{1.7} \mathrm{Cr}_{0.3} \mathrm{O}_{3}$ and $\mathrm{Fe}_{1.2} \mathrm{Cr}_{0.6} \mathrm{O}_{3}$. The results of SEM-EDS are given in Figure 9. It can be seen that the inner structure of the oxidized HCVTM pellets was compact, which indicated the successful and sufficient oxidation consolidation.

Table 2. Chemical composition of the oxidized HCVTM pellets (wt \%).

\begin{tabular}{ccccccccc}
\hline $\mathrm{TFe}$ & $\mathrm{FeO}$ & $\mathrm{TiO}_{2}$ & $\mathrm{~V}_{\mathbf{2}} \mathrm{O}_{5}$ & $\mathrm{Cr}_{2} \mathrm{O}_{3}$ & $\mathrm{Al}_{2} \mathrm{O}_{3}$ & $\mathrm{SiO}_{2}$ & $\mathrm{MgO}$ & $\mathrm{CaO}$ \\
\hline 59.46 & 0.50 & 4.49 & 0.91 & 0.59 & 3.07 & 2.03 & 1.03 & 0.21 \\
\hline
\end{tabular}




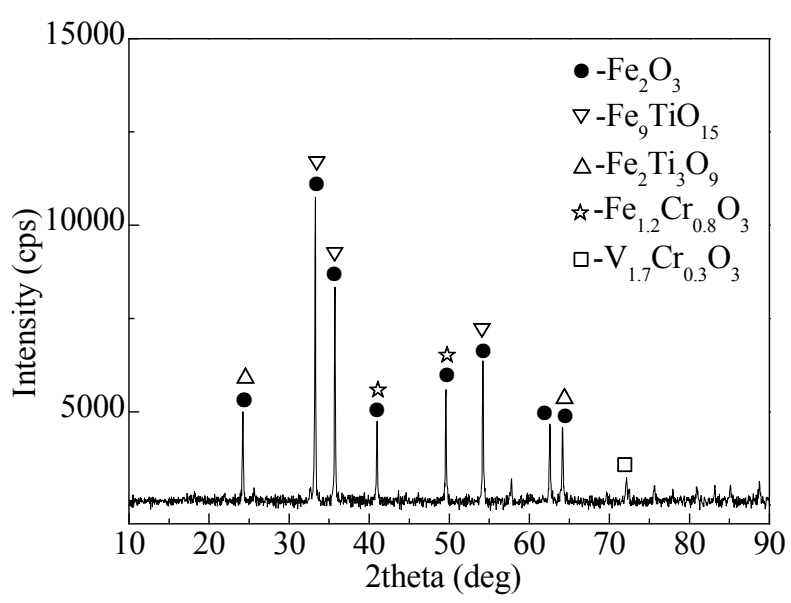

Figure 8. XRD analysis of the oxidized HCVTM pellets.
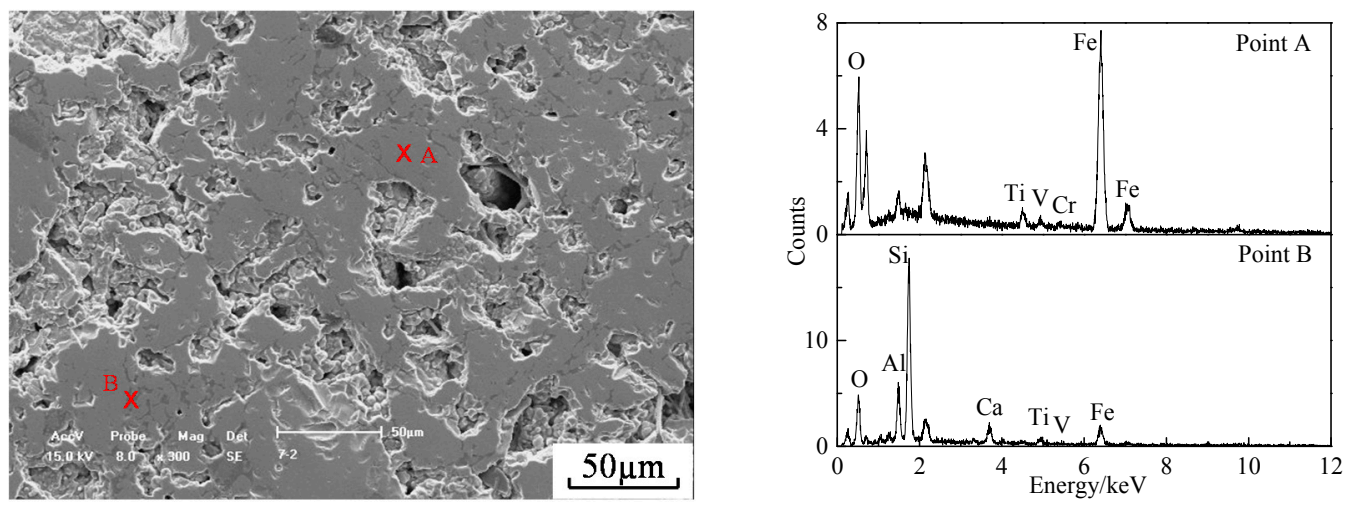

Figure 9. Scanning electron microscopy-energy dispersive spectrometer (SEM-EDS) analysis of the oxidized HCVTM pellets (A-gray phase; B-dark gray phase).

\subsection{Effects of Heating Rate and Gas Composition on the HCVTM Pellet Reduction Ratio}

The effects of the heating rate on the non-isothermal reduction ratio of HCVTM pellets under different reducing gas compositions are shown in Figure 10. According to the change rule of the reduction ratio, each of these plots could be divided into three distinct regions. Initially, the pellet reduction was insensitive and its rate was slow, indicating a modest reduction ratio. Then, the reduction accelerated suddenly at approximately $773 \mathrm{~K}$, although the accurate turn temperature was slightly different with different heating rates. As the reduction proceeded, the reduction rate decreased due to the thickening product layer, and the reduction ratio nearly reached a high constant value. In addition, it is clear that the reduction ratio plots shifted to the right (to increasing temperature values) with an increasing heating rate. Moreover, the HCVTM pellets nearly reached the same reduction ratio under a given reducing gas composition, although the heating rates were different.

The effects of the reducing gas composition on the non-isothermal reduction ratio with different heating rates are presented in Figure 11. It is obvious that the reduction ratio reached a higher value with an increasing content of the $\mathrm{H}_{2}$ in the gas mixtures. This result is attributed to the accelerated reduction by the $\mathrm{H}_{2}$-rich atmosphere. The $\mathrm{H}_{2}$ molecule is smaller than the other gas molecules, which is conducive to a more effective diffusion. Moreover, according to the work of Ono-Nakazato et al. [21], some of the $\mathrm{H}_{2}$ molecules act as catalysts during the reduction. All these factors can accelerate and improve the reduction. 

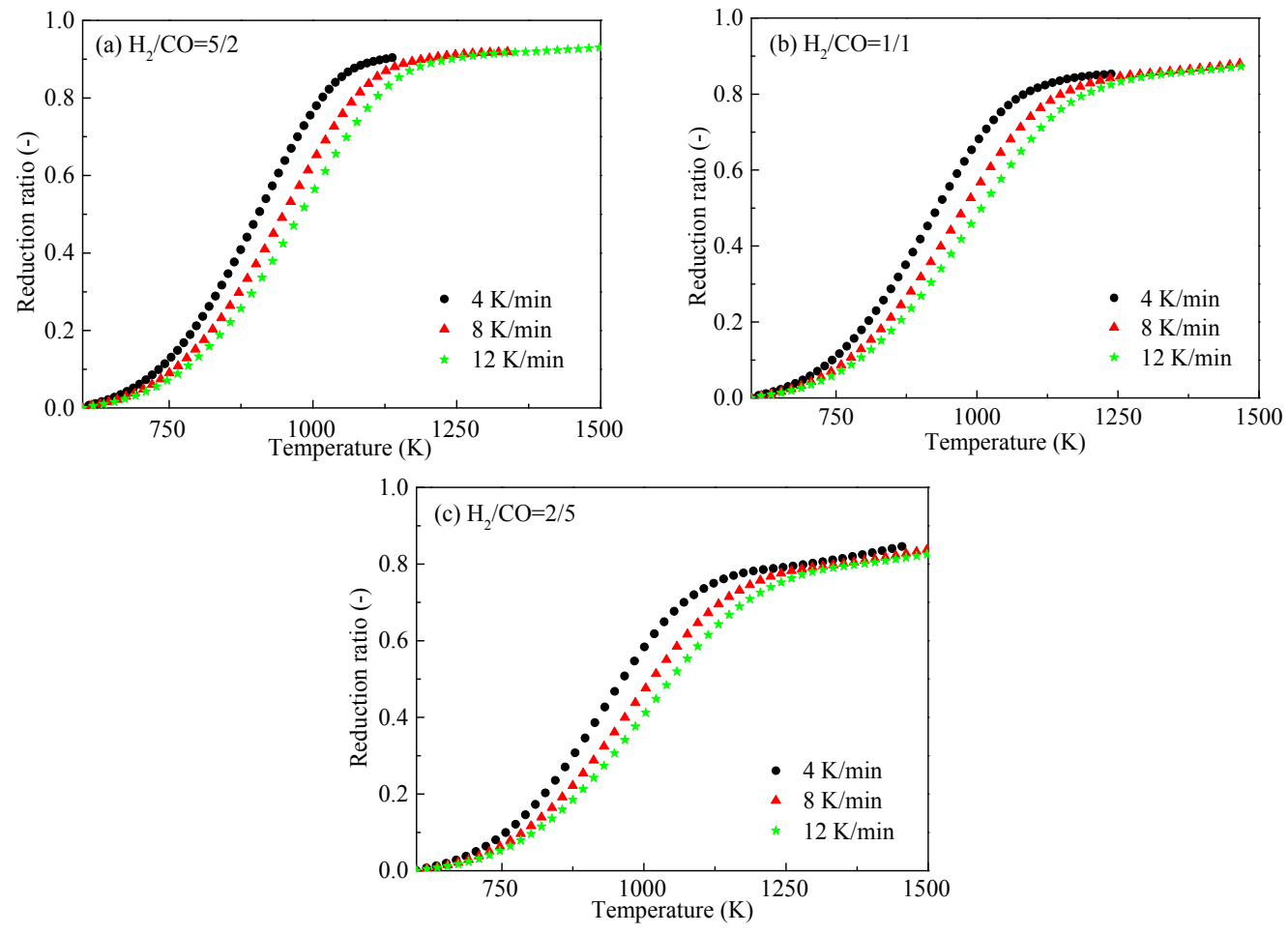

Figure 10. Effects of the heating rate on the non-isothermal reduction ratio under different reducing gas compositions (a) $\mathrm{H}_{2} / \mathrm{CO}=5 / 2 ;(\mathbf{b}) \mathrm{H}_{2} / \mathrm{CO}=1 / 1$; (c) $\mathrm{H}_{2} / \mathrm{CO}=2 / 5$.
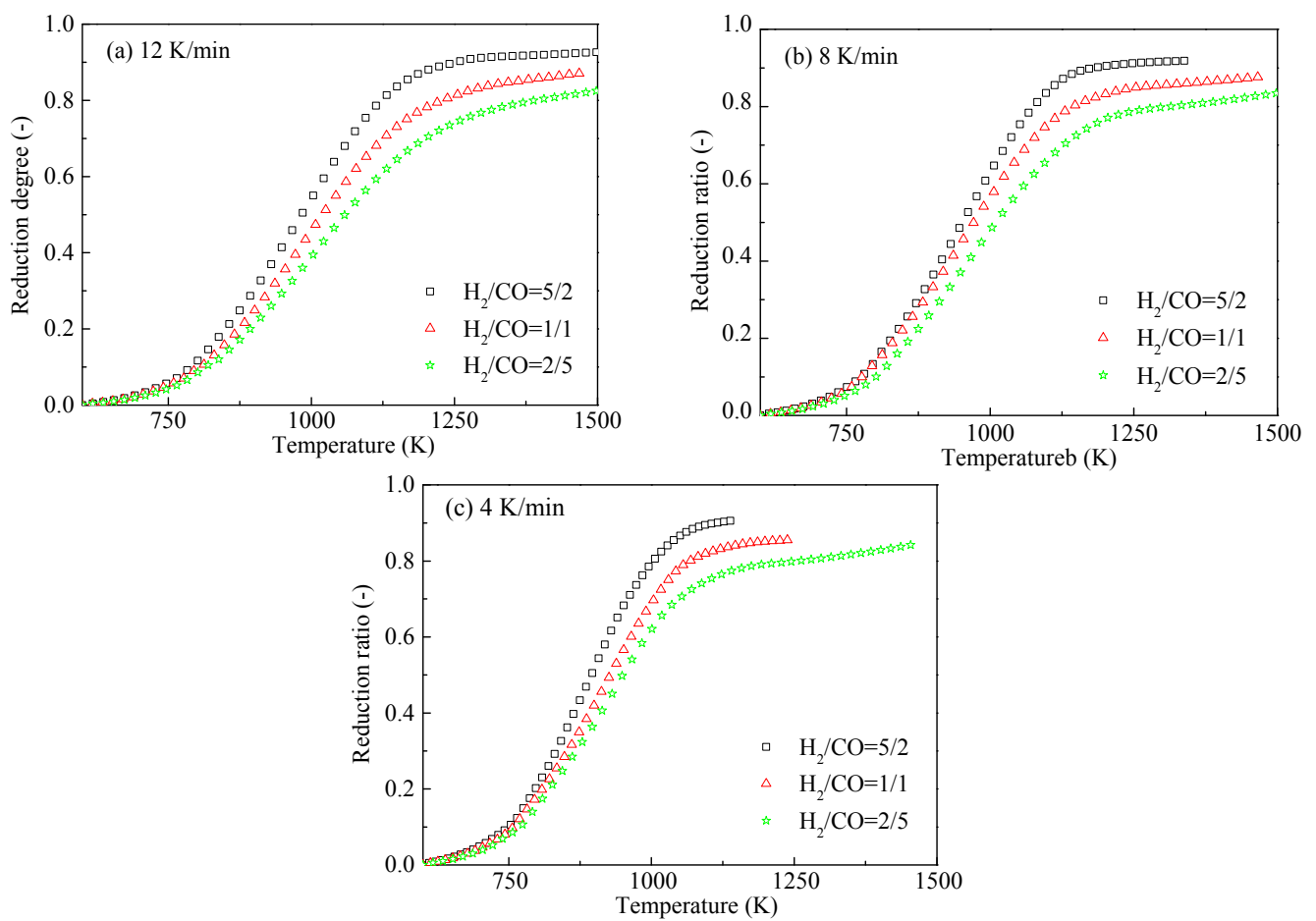

Figure 11. Effects of the reducing gas composition on the non-isothermal reduction ratio with different heating rates (a) $12 \mathrm{~K} / \mathrm{min}$; (b) $8 \mathrm{~K} / \mathrm{min}$; (c) $4 \mathrm{~K} / \mathrm{min}$. 


\subsection{Phase Transformation and Morphologic Changes of the HCVTM Pellets During Reduction}

To investigate the phase transformation during the gas-based reduction, the HCVTM pellets were reduced under a heating rate of $8 \mathrm{~K} / \mathrm{min}$ and a gas composition of $\mathrm{H}_{2} / \mathrm{CO}=5 / 2$ and were analyzed by XRD. Several cases with a specific reduction ratio $(0 \%, 15 \%, 30 \%, 60 \%, 80 \%, 90 \%$, and $92 \%)$ were considered, and the results are given in Figure 12 and Table 3. As seen in Figure 12a, the main phases in the oxidized HCVTM pellets were hematite $\left(\mathrm{Fe}_{2} \mathrm{O}_{3}\right)$, titanohematite $\left(\mathrm{TTH}, \mathrm{Fe}_{9} \mathrm{TiO}_{15}\right)$, pseudorutile $\left(\mathrm{Fe}_{2} \mathrm{Ti}_{3} \mathrm{O}_{9}\right)$, Fe-Cr oxide solid solution $\left(\mathrm{Fe}_{1.2} \mathrm{Cr}_{0.8} \mathrm{O}_{3}\right)$, and $\mathrm{V}$-Cr oxide solid solution $\left(\mathrm{V}_{1.7} \mathrm{Cr}_{0.3} \mathrm{O}_{3}\right)$. From Figure $12 \mathrm{~b}$, as the reduction proceeded, the reduction ratio reached $15 \%$, and the diffraction peak of the hematite disappeared since it was transformed into magnetite $\left(\mathrm{Fe}_{3} \mathrm{O}_{4}\right)$. Meanwhile, titanomagnetite (TTM, $\mathrm{Fe}_{2.75} \mathrm{Ti}_{0.25} \mathrm{O}_{4}$ ) was observed to be present, and the solid solutions including Fe-Cr and $\mathrm{V}-\mathrm{Cr}$ were changed into chromite $\left(\mathrm{FeCr}_{2} \mathrm{O}_{4}\right)$ and coulsonite $\left(\mathrm{Fe}_{2} \mathrm{VO}_{4}\right)$, respectively. In Figure 12c, when the reduction ratio was $30 \%$, metallic iron $(\mathrm{Fe})$ was generated by further reduction, and the diffraction peak of wustite $(\mathrm{FeO})$ was detected. However, by this time, the magnetite was still the dominant phase in the HCVTM pellets. As shown in Figure 12d, with the continuous removal of oxygen during the reduction process, the reduction ratio increased to $60 \%$; although the phase compositions had no changes, the diffraction peaks for each existing phase were entirely different. Clearly, the magnetite and titanomagnetite peaks were both weakened, while the metallic iron peaks were enhanced. Meanwhile, wustite also showed an increasing tendency. In Figure 12e, further increasing the reduction ratio up to $80 \%$ had no obvious effects on the phase type, however, a slight decrease of wustite peak intensity as well as the sharpening Fe peaks could be found. As shown in Figure 12f, neither magnetite nor titanomagnetite could be detected at the reduction ratio of $90 \%$, but the new ilmenite $\left(\mathrm{FeTiO}_{3}\right)$ phase appeared. In Figure 12g, a further increase in the reduction ratio to $92 \%$ resulted in the presence of $\mathrm{Ti}$ in the form of titanium oxide $\left(\mathrm{TiO}_{2}\right)$.

After the non-isothermal reduction by the $\mathrm{H}_{2}-\mathrm{CO}-\mathrm{CO}_{2}$ mixtures was complete, the two detected phases in the final reduced HCVTM pellets were metallic iron $(\mathrm{Fe})$ and titanium oxide $\left(\mathrm{TiO}_{2}\right)$. The phases bearing $\mathrm{V}$ or $\mathrm{Cr}$ were not found after the reduction ratio of $80 \%$, which might result from their relatively low content in HCVTM and the limitations of the analysis method. As the reduction proceeded, the diffraction peaks of the phases containing $\mathrm{V}$ or $\mathrm{Cr}$ became less sensitive. Therefore, in this work, the phase transformations of $\mathrm{V}$ or $\mathrm{Cr}$ are analyzed before the reduction ratio of $80 \% \mathrm{~V}$ and $\mathrm{Cr}$ are present in the form of coulsonite $\left(\mathrm{Fe}_{2} \mathrm{VO}_{4}\right)$ and chromite $\left(\mathrm{FeCr}_{2} \mathrm{O}_{4}\right)$, respectively.

Table 3. Phase compositions of the HCVTM pellets at different reduction ratios.

\begin{tabular}{cc}
\hline Reduction Ratio (\%) & Phase Composition \\
\hline 0 & $\mathrm{Fe}_{2} \mathrm{O}_{3}, \mathrm{Fe}_{9} \mathrm{TiO}_{15}, \mathrm{~V}_{1.7} \mathrm{Cr}_{0.3} \mathrm{O}_{3}, \mathrm{Fe}_{1.2} \mathrm{Cr}_{0.8} \mathrm{O}_{3}, \mathrm{Fe}_{2} \mathrm{Ti}_{3} \mathrm{O}_{9}$ \\
15 & $\mathrm{Fe}_{3} \mathrm{O}_{4}, \mathrm{Fe}_{2.75} \mathrm{Ti}_{0.25} \mathrm{O}_{4}, \mathrm{Fe}_{2} \mathrm{VO}_{4}, \mathrm{FeCr}_{2} \mathrm{O}_{4}$ \\
30 & $\mathrm{Fe}, \mathrm{Fe}_{3} \mathrm{O}_{4}, \mathrm{FeO}, \mathrm{Fe}_{2.75} \mathrm{Ti}_{0.25} \mathrm{O}_{4}, \mathrm{Fe}_{2} \mathrm{VO}_{4}, \mathrm{FeCr}_{2} \mathrm{O}_{4}$ \\
60 & $\mathrm{Fe}, \mathrm{Fe}_{3} \mathrm{O}_{4}, \mathrm{FeO}, \mathrm{Fe}_{2.75} \mathrm{Ti}_{0.25} \mathrm{O}_{4}, \mathrm{Fe}_{2} \mathrm{VO}_{4}, \mathrm{FeCr}_{2} \mathrm{O}_{4}$ \\
80 & $\mathrm{Fe}, \mathrm{Fe}_{3} \mathrm{O}_{4}, \mathrm{FeO}, \mathrm{Fe}_{2.75} \mathrm{Ti}_{0.25} \mathrm{O}_{4}, \mathrm{Fe}_{2} \mathrm{VO}_{4}, \mathrm{FeCr}_{2} \mathrm{O}_{4}$ \\
90 & $\mathrm{Fe}, \mathrm{FeO}, \mathrm{FeTiO}$ \\
92 & $\mathrm{Fe}, \mathrm{TiO}_{2}$ \\
\hline
\end{tabular}




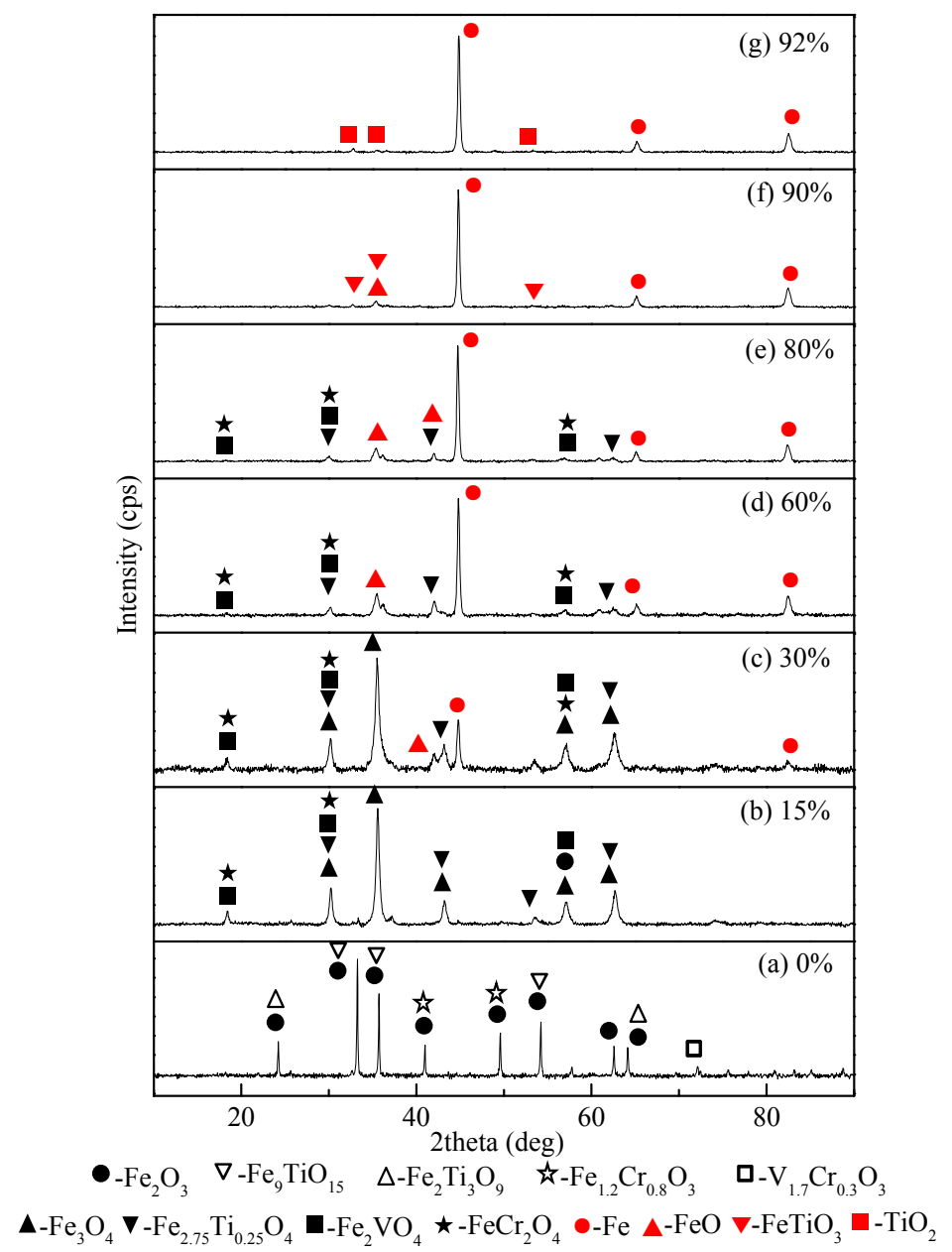

Figure 12. XRD analysis of the HCVTM pellets with different reduction ratios, (a) $0 \%$ (b) $15 \%$ (c) $30 \%$ (d) $60 \%$ (e) $80 \%$ (f) $90 \%$ (g) $92 \%$.

Notably, as seen from the XRD patterns in Figure 12, the peaks of the phases containing Ti, V, and Cr mostly overlapped, which was attributed to the close coexistence of these three elements in the HCVTM. Generally, $\mathrm{V}$ existed in an isomorphic form with $\mathrm{Ti}$, and the occurrence of the $\mathrm{Cr}$ distribution was similar to that of $\mathrm{V}$, as described in the work of $\mathrm{He}$ [22]. Meanwhile, the mineralogical investigation indicates that $\mathrm{V}$ and $\mathrm{Cr}$ concentrations above $97 \%$ were embedded into the titanomagnetite. In addition, the octahedral sites of the $\mathrm{V}$ and $\mathrm{Cr}$ were occupied by trivalent ions such as $\mathrm{V}$ (III) and $\mathrm{Cr}$ (III), similar to the results of Zhao [23]. Therefore, the phases bearing Ti, V, and $\mathrm{Cr}$ are usually found together with overlapped diffraction peaks, similar to the results of Zhou [24]. Currently, research concerning VTM or HCVTM utilizes XRD analysis as the main method to initially identify the formation of Ti-bearing phases, V-bearing phases, and Cr-bearing phases, as reported in many references. Therefore, based on the reasonable XRD analyses, the non-isothermal reduction of HCVTM pellets by gas mixtures can be speculated to proceed according to the following reactions, expressed in Equations (2)-(8). Here, the reduction by $\mathrm{H}_{2}$ is taken as an example.

(1) When the reduction begins:

$$
36 \mathrm{Fe}_{2} \mathrm{O}_{3}+2 \mathrm{Fe}_{2} \mathrm{Ti}_{3} \mathrm{O}_{9}+2 \mathrm{Fe}_{9} \mathrm{TiO}_{15}+20 \mathrm{H}_{2}=2 \mathrm{Fe}_{3} \mathrm{O}_{4}+8\left(3 \mathrm{Fe}_{3} \mathrm{O}_{4} \cdot \mathrm{Fe}_{2} \mathrm{TiO}_{4}\right)+20 \mathrm{H}_{2} \mathrm{O}
$$

Meanwhile, the phases containing $\mathrm{V}$ or $\mathrm{Cr}$ also cause some changes, as shown in Equations (2)-(5).

$$
\mathrm{V}_{1.7} \mathrm{Cr}_{0.3} \mathrm{O}_{3}=0.85 \mathrm{~V}_{2} \mathrm{O}_{3}+0.15 \mathrm{Cr}_{2} \mathrm{O}_{3}
$$




$$
\begin{gathered}
\mathrm{Fe}_{1.2} \mathrm{Cr}_{0.8} \mathrm{O}_{3}=0.4 \mathrm{Cr}_{2} \mathrm{O}_{3}+0.6 \mathrm{Fe}_{2} \mathrm{O}_{3} \\
\mathrm{Fe}_{3} \mathrm{O}_{4}+3 \mathrm{Cr}_{2} \mathrm{O}_{3}+\mathrm{H}_{2}=3 \mathrm{FeCr}_{2} \mathrm{O}_{4}+\mathrm{H}_{2} \mathrm{O} \\
4 \mathrm{Fe}_{3} \mathrm{O}_{4}+3 \mathrm{~V}_{2} \mathrm{O}_{3}+\mathrm{H}_{2}=6 \mathrm{Fe}_{2} \mathrm{VO}_{4}+\mathrm{H}_{2} \mathrm{O}
\end{gathered}
$$

(2) When the reduction ratio is $15-90 \%$ :

$$
\mathrm{Fe}_{3} \mathrm{O}_{4}+3 \mathrm{Fe}_{3} \mathrm{O}_{4} \cdot \mathrm{Fe}_{2} \mathrm{TiO}_{4}+14 \mathrm{H}_{2}=11 \mathrm{FeO}+\mathrm{FeTiO}_{3}+14 \mathrm{H}_{2} \mathrm{O}
$$

(3) When the reduction ratio is more than $90 \%$ :

$$
\mathrm{FeO}+\mathrm{FeTiO}_{3}+2 \mathrm{H}_{2}=2 \mathrm{Fe}+\mathrm{TiO}_{2}+2 \mathrm{H}_{2} \mathrm{O}
$$

Therefore, the transformations of the key phases during the HCVTM pellet non-isothermal gas-based direct reduction are listed as follows: $\mathrm{Fe}_{2} \mathrm{O}_{3} \rightarrow \mathrm{Fe}_{3} \mathrm{O}_{4} \rightarrow \mathrm{FeO} \rightarrow \mathrm{Fe} ; \mathrm{Fe}_{9} \mathrm{TiO}_{15}+\mathrm{Fe}_{2} \mathrm{Ti}_{3} \mathrm{O}_{9} \rightarrow$ $\mathrm{Fe}_{2.75} \mathrm{Ti}_{0.25} \mathrm{O}_{4} \rightarrow \mathrm{FeTiO}_{3} \rightarrow \mathrm{TiO}_{2} ; \mathrm{V}_{1.7} \mathrm{Cr}_{0.3} \mathrm{O}_{3} \rightarrow \mathrm{V}_{2} \mathrm{O}_{3} \rightarrow \mathrm{Fe}_{2} \mathrm{VO}_{4} ; \mathrm{Fe}_{1.2} \mathrm{Cr}_{0.8} \mathrm{O}_{3} \rightarrow \mathrm{Cr}_{2} \mathrm{O}_{3} \rightarrow \mathrm{FeCr}_{2} \mathrm{O}_{4}$.

The morphology changes of the HCVTM pellets during the non-isothermal gas-based direct reduction were investigated by SEM analysis, as shown in Figure 13. The reduction swelling index (RSI) is defined as the volume change after reduction. The RSI changed with the increasing reduction ratio, as presented in Figure 14. Initially, (Figure 13a,b), the reduction began, and the compact recrystallization of the hematite was significantly destroyed, leading to the loose inner structure of the HCVTM pellets and the sharp increase of the RSI. As the reduction proceeded (Figure 13c), the reduction ratio increased to $60 \%$, and the large-scale bright white metallic iron was found in the pellets, which agrees well with the results from the XRD analysis (Figure 13d). After further increasing the reduction ratio (Figure 13e,f), more metallic iron was generated, grew, and gradually gathered. Meanwhile, the generated metallic iron introduced the softening deformation at high reduction temperatures. Both the above functions are conducive to a decrease in the number of pores in the pellets. Accordingly, the RSI slightly decreased during the late stage of the reduction, as shown in Figure 14.
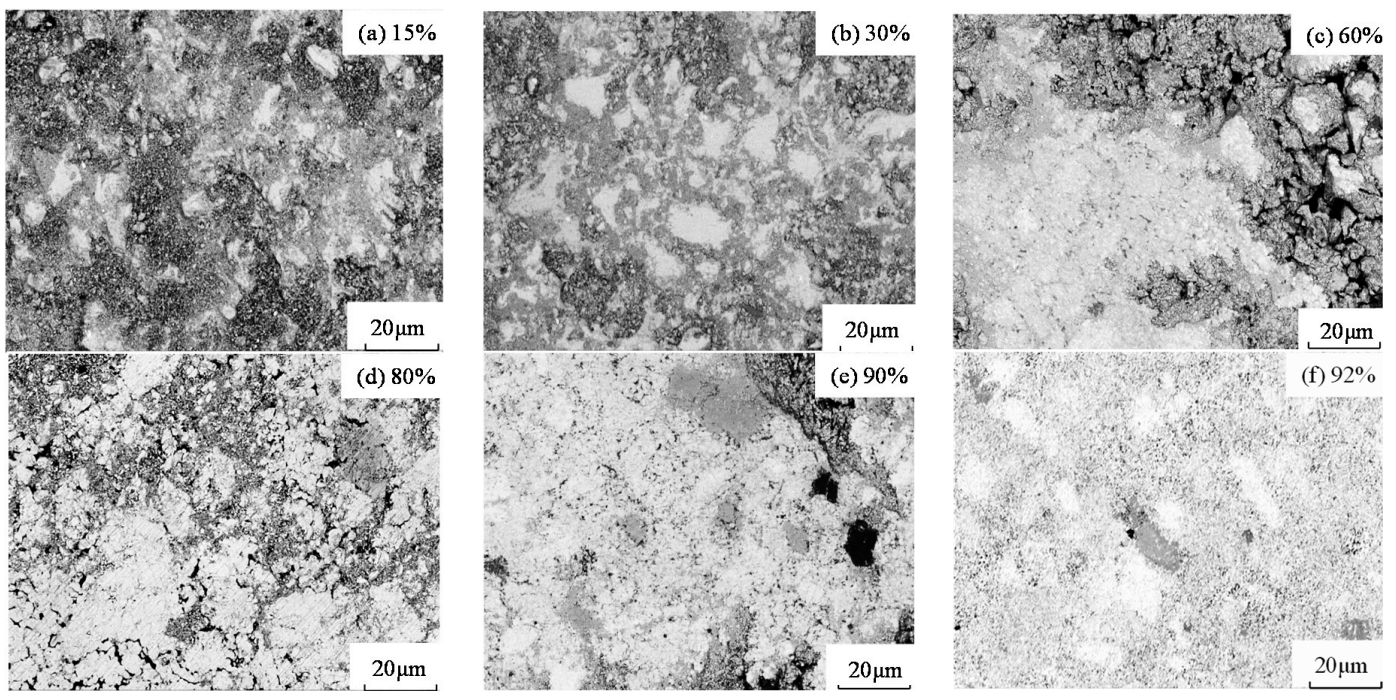

Figure 13. Morphology changes of the HCVTM pellets during the non-isothermal gas-based direct reduction ratios. (a) $15 \%$; (b) $30 \%$; (c) $60 \%$; (d) $80 \%$; (e) $90 \%$; (f) $92 \%$. 


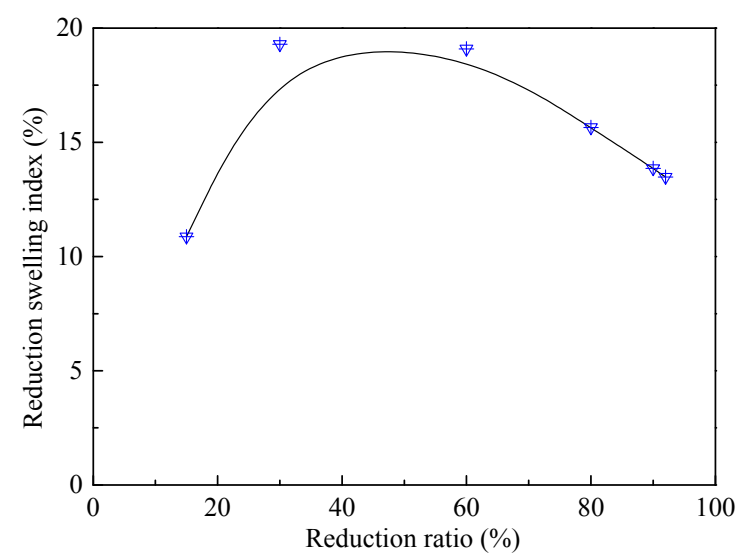

Figure 14. Changes in the reduction swelling index (RSI) with the increasing reduction ratio.

\subsection{Non-Isothermal Gas-Based Direct Reduction Kinetics of HCVTM Pellets}

The phases bearing $\mathrm{V}$ and $\mathrm{Cr}$ were difficult to reduce under the experimental temperatures and gas compositions. In addition, the amounts of $\mathrm{V}$ and $\mathrm{Cr}$ in the HCVTM were relatively low. Therefore, the possible reaction interfaces were confirmed by the transformations of the phases containing $\mathrm{Fe}$ and Ti when performing the kinetic analysis. According to the results of the XRD analysis and the conclusion of the phase transformation, the reactions are presented as Equations (9)-(11).

$$
\begin{gathered}
\mathrm{Fe}_{2} \mathrm{O}_{3}+\mathrm{Fe}_{2} \mathrm{Ti}_{3} \mathrm{O}_{9}+\mathrm{TTH}+\mathrm{H}_{2}(\mathrm{CO}) \rightarrow \mathrm{Fe}_{3} \mathrm{O}_{4}+\mathrm{TTM}+\mathrm{H}_{2} \mathrm{O}\left(\mathrm{CO}_{2}\right) \\
\mathrm{Fe}_{3} \mathrm{O}_{4}+\mathrm{TTM}+\mathrm{H}_{2}(\mathrm{CO}) \rightarrow \mathrm{FeO}+\mathrm{FeTiO}_{3}+\mathrm{H}_{2} \mathrm{O}\left(\mathrm{CO}_{2}\right) \\
\mathrm{FeO}+\mathrm{FeTiO}_{3}+\mathrm{H}_{2}(\mathrm{CO}) \rightarrow \mathrm{Fe}+\mathrm{TiO}_{2}+\mathrm{H}_{2} \mathrm{O}\left(\mathrm{CO}_{2}\right)
\end{gathered}
$$

It is concluded that the above reactions in Equations (9)-(11) occurred simultaneously. This gas-based reduction mechanism could be described by an initial reduction process among the hematite, pseudorutile, titanohematite, and the reducing gas at the outer surface of the particles, forming the magnetite and titanomagnetite. Once the magnetite and titanomagnetite formed, the second reaction proceeded immediately. Using this analogy, the third reaction began once the products of the second reaction (wustite and ilmenite) were generated. Therefore, it is assumed that the gas-based reduction of the HCVTM pellets proceeded topochemically and had three reaction fronts corresponding to Equations (9)-(11), as presented in Figure 15.

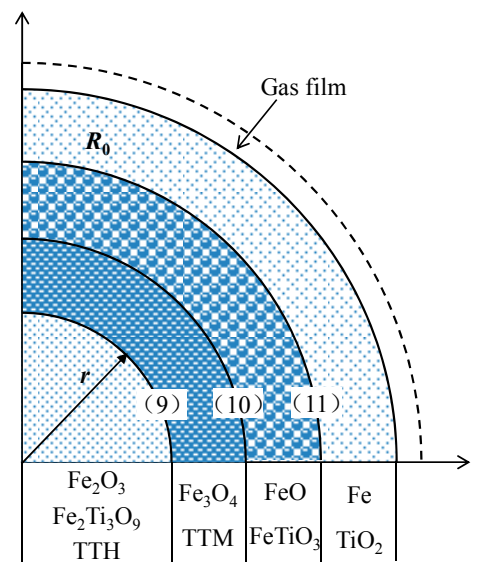

Figure 15. Schematic diagram of the interface progressions for the gas-based reduction of the HCVTM pellets. 
Based on earlier works [24,25], when there is only one reaction interface and the reducing gas is $\mathrm{H}_{2}$ or $\mathrm{CO}$, the formula to describe the reduction ratio $\xi$ of spherical particles is expressed as Equations (12) and (13), corresponding to the two cases of controlling the chemical reaction and controlling the diffusion in the product layer, respectively:

$$
\begin{gathered}
\xi=1-\left(1-\frac{1}{B_{C}} \exp \left(-\frac{\Delta E_{\text {app }}}{R T}\right) t\right)^{3} \\
\xi=1-\left[1-\sqrt{\frac{1}{B_{\mathrm{D}}} \exp \left(-\frac{\Delta E_{\text {app }}}{R T}\right) t}\right]^{3}
\end{gathered}
$$

where $B_{C}$ and $B_{\mathrm{D}}$ are the coefficients related to the chemical reaction and the diffusion in the product layer, respectively; $\Delta E_{\text {app }}$ is the apparent activation energy for the reaction, $\mathrm{J} / \mathrm{mol} ; R$ is the gas constant, $\mathrm{J} /(\mathrm{mol} \cdot \mathrm{K}) ; T$ is the temperature at time $t, \mathrm{~K}$; and $t$ is the reduction time, s.

In the present work, the relationship between the temperature and time is obtained from Equation (14):

$$
t=\frac{T-T_{0}}{\beta}
$$

where $T$ is the temperature at time $t, \mathrm{~K} ; T_{0}$ is the initial temperature, $\mathrm{K}$; and $\beta$ is the heating rate, $\mathrm{K} / \mathrm{min}$.

Therefore, Equations (12) and (13) can be expressed as into Equations (15) and (16), respectively.

$$
\begin{gathered}
\xi=1-\left(1-\frac{1}{B_{C}} \exp \left(-\frac{\Delta E_{\text {app }}}{R T}\right) \frac{T-T_{0}}{\beta}\right)^{3} \\
\xi=1-\left[1-\sqrt{\frac{1}{B_{D}} \exp \left(-\frac{\Delta E_{\text {app }}}{R T}\right) \frac{T-T_{0}}{\beta}}\right]^{3}
\end{gathered}
$$

For the non-isothermal reduction of the HCVTM pellets by gas mixtures, considering the reducing gas composition and the three reaction interfaces, the overall reduction ratio can be expressed as a linear summation, defined in Equation (17):

$$
\begin{aligned}
\xi & =x_{\mathrm{H}_{2}} \xi_{\mathrm{H}_{2}}+x_{\mathrm{CO}} \xi_{\mathrm{CO}} \\
& =x_{\mathrm{H}_{2}}\left(\alpha_{1 \mathrm{H}_{2}} \xi_{1 \mathrm{H}_{2}}+\alpha_{2 \mathrm{H}_{2}} \xi_{2 \mathrm{H}_{2}}+\alpha_{3 \mathrm{H}_{2}} \xi_{3 \mathrm{H}_{2}}\right)+x_{\mathrm{CO}}\left(\alpha_{1 \mathrm{CO}} \xi_{1 \mathrm{CO}}+\alpha_{2} \mathrm{CO} \xi_{2} \mathrm{CO}+\alpha_{3 \mathrm{CO}} \xi_{3 \mathrm{CO}}\right)
\end{aligned}
$$

where $x_{\mathrm{H}_{2}}$ and $x_{\mathrm{CO}}$ are the mole fractions of $\mathrm{H}_{2}$ and $\mathrm{CO}$, respectively, \%; $\xi_{\mathrm{H}_{2}}$ and $\xi_{\mathrm{CO}}$ are the reduction ratios by $\mathrm{H}_{2}$ and $\mathrm{CO}$, respectively, \%; $\xi_{1 \mathrm{H}_{2}}, \xi_{2 \mathrm{H}_{2}}$, and $\xi_{3 \mathrm{H}_{2}}$ are the reduction ratios of Reactions (9)-(11) by $\mathrm{H}_{2}$, respectively, \%; $\xi_{1 \mathrm{CO}}, \xi_{2} \mathrm{CO}$, and $\xi_{3 \mathrm{CO}}$ are the reduction ratios of Reactions (9)-(11) by $\mathrm{CO}$, respectively, $\% ; \alpha_{1 \mathrm{H}_{2}}, \alpha_{2 \mathrm{H}_{2}}$, and $\alpha_{3 \mathrm{H}_{2}}$ are the coefficients depending on the oxygen loss of Reactions (9)-(11) by $\mathrm{H}_{2}$, respectively; and $\alpha_{1 \mathrm{CO}}, \alpha_{2} \mathrm{CO}$, and $\alpha_{3 \mathrm{CO}}$ are the coefficients depending on the oxygen loss of Reactions (9)-(11) by CO, respectively. For simplicity, $\alpha$ was approximated according to hematite $\rightarrow$ magnetite, magnetite $\rightarrow$ wustite, and wustite $\rightarrow$ iron, namely, $\alpha_{1 \mathrm{H}_{2}}=\alpha_{1 \mathrm{CO}}=1 / 9$, $\alpha_{2 \mathrm{H}_{2}}=\alpha_{2 \mathrm{CO}}=2 / 9$, and $\alpha_{3 \mathrm{H}_{2}}=\alpha_{3 \mathrm{CO}}=6 / 9$.

For Reaction (9), due to the three forming and growing product layers, including magnetite and titanomagnetite, wustite and ilmenite, and iron and titanium oxide, the diffusion of the reducing gas through the magnetite and titanomagnetite product layer was weakened. Moreover, a significant amount of $\mathrm{H}_{2}$ was consumed during the reactions at the interfaces of Reactions (10) and (11). Thus, maybe the diffusion in product layers was the restrictive step. For Reactions (10) and (11) as first seen in Figure 8, several pores remained in the outer products, which promoted gas diffusion. Second, if Reactions (10) and (11) are controlled by the diffusion in the product layer, then the reducing gas will run out before it diffuses into the first interface (9), and Reaction (9) will not occur. Hence, it is reasonable to speculate that Reactions (10) and (11) are most likely controlled by chemical reactions. 
These above assumptions were similarly applied by Chou when researching the reduction of metal oxides by $\mathrm{H}_{2}[25,26]$.

Based on the above, $\xi_{1 \mathrm{H}_{2}}$ and $\xi_{1 \mathrm{CO}}$ are expressed as in Equation (16), while $\xi_{2 \mathrm{H}_{2}}, \xi_{3 \mathrm{H}_{2}}, \xi_{22 \mathrm{CO}}$, and $\xi_{3 \mathrm{CO}}$ are expressed as in Equation (15). The overall reduction ratio is evaluated by Equation (18):

$$
\begin{aligned}
& \xi=1-x_{\mathrm{H}_{2}}\left\{\frac{1}{9}\left[1-\sqrt{\frac{\exp \left(-\frac{\Delta E_{\text {ap }}^{\mathrm{H}_{2}}}{R T}\right)}{B_{\mathrm{D}_{1}}^{\mathrm{H}_{2}}} \frac{T-T_{0}}{\beta}}\right]^{3}+\frac{2}{9}\left[1-\frac{\exp \left(-\frac{\Delta E_{\text {app }}^{\mathrm{H}_{2}}}{R T}\right)}{B_{\mathrm{C}_{2}}^{\mathrm{H}_{2}}} \frac{T-T_{0}}{\beta}\right]^{3}+\frac{6}{9}\left[1-\frac{\exp \left(-\frac{\Delta E_{\text {app }}^{\mathrm{H}_{2}}}{R T}\right)}{B_{\mathrm{C}_{3}}^{\mathrm{H}_{2}}} \frac{T-T_{0}}{\beta}\right]^{3}\right]^{3} \\
& -x_{\mathrm{CO}}\left\{\frac{1}{9}\left[1-\sqrt{\frac{\exp \left(-\frac{\Delta E_{\mathrm{app}}}{R T}\right)}{B_{\mathrm{D}_{1}}^{\mathrm{CO}}} \frac{T-T_{0}}{\beta}}\right]^{3}+\frac{2}{9}\left[1-\frac{\exp \left(-\frac{\Delta E_{\text {app }}^{\mathrm{CO}}}{R T}\right)}{B_{\mathrm{C}_{2}}^{\mathrm{CO}}} \frac{T-T_{0}}{\beta}\right]^{3}+\frac{6}{9}\left[1-\frac{\exp \left(-\frac{\Delta E_{\text {app }}^{\mathrm{CO}}}{R T}\right)}{B_{\mathrm{C}_{3}}^{\mathrm{CO}}} \frac{T-T_{0}}{\beta}\right]^{3}\right\}
\end{aligned}
$$

where $x_{\mathrm{H}_{2}}$ and $x_{\mathrm{CO}}$ are the mole fractions in $\mathrm{H}_{2}$ and $\mathrm{CO}$, respectively, \%; $\Delta E_{\mathrm{app}_{1}}^{\mathrm{H}_{2}}, \Delta E_{\mathrm{app}_{2}}^{\mathrm{H}_{2}}, \Delta E_{\mathrm{app}_{3}}^{\mathrm{H}_{2}}$, $\Delta E_{\mathrm{app}_{1}}^{\mathrm{CO}}, \Delta E_{\mathrm{app}_{2}}^{\mathrm{CO}}$, and $\Delta E_{\mathrm{app}_{3}}^{\mathrm{CO}}$ are the apparent activation energies for Reactions (9)-(11) by $\mathrm{H}_{2}$ and $\mathrm{CO}$, respectively, J/mol; $T$ is the temperature at time $t, \mathrm{~K} ; T_{0}$ is the initial temperature, $\mathrm{K} ; \beta$ is the heating rate, $\mathrm{K} / \mathrm{min}$; and $B_{\mathrm{D}_{1}}^{\mathrm{H}_{2}}, B_{\mathrm{C}_{2}}^{\mathrm{H}_{2}}, B_{\mathrm{C}_{3}}^{\mathrm{H}_{2}}, B_{\mathrm{D}_{1}}^{\mathrm{CO}}, B_{\mathrm{C}_{2}}^{\mathrm{CO}}$, and $B_{\mathrm{C}_{3}}^{\mathrm{CO}}$ are the coefficients related to the chemical reaction and diffusion when reduced by $\mathrm{H}_{2}$ and $\mathrm{CO}$, respectively.

Using the non-isothermal experimental data and using a MATLAB program, the kinetic parameters of Equation (18) were obtained, as listed in Table 4. The final non-isothermal reduction kinetic model of the HCVTM pellets by gas mixtures can be expressed as Equation (19). When the heating rate along with the reducing gas composition is given, the specific non-isothermal reduction model for the HCVTM pellet by gas mixtures can be determined.

Table 4. The kinetic parameters for the non-isothermal reduction model for HCVTM pellets by gas mixtures.

\begin{tabular}{ccccccc}
\hline \multirow{2}{*}{ Parameter } & \multicolumn{5}{c}{$\Delta E_{\mathrm{app}} \times 10^{3}(\mathrm{~J} / \mathbf{m o l})$} \\
\cline { 2 - 7 } & $\Delta E_{\mathrm{app}_{1}}^{\mathrm{H}_{2}}$ & $\Delta E_{\mathrm{app}_{2}}^{\mathrm{H}_{2}}$ & $\Delta E_{\mathrm{app}_{3}}^{\mathrm{H}_{2}}$ & $\Delta E_{\mathrm{app}_{1}}^{\mathrm{CO}}$ & $\Delta E_{\mathrm{app}_{2}}^{\mathrm{CO}}$ & $\Delta E_{\mathrm{app}_{2}}^{\mathrm{CO}}$ \\
\hline Value & 90.64 & 83.98 & 171.80 & 145.94 & 158.51 & 83.79 \\
\hline \multirow{2}{*}{ Parameter } & \multicolumn{5}{c}{$B_{\mathrm{C}}$ or $B_{\mathrm{D}} \times 10^{-2}(-)$} \\
\cline { 2 - 7 } & $B_{\mathrm{D}_{1}}^{\mathrm{H}_{2}}$ & $B_{\mathrm{C}_{2}}^{\mathrm{H}_{2}}$ & $B_{\mathrm{C}_{3}}^{\mathrm{H}_{2}}$ & $B_{\mathrm{D}_{1}}^{\mathrm{CO}}$ & $B_{\mathrm{C}_{2}}^{\mathrm{CO}}$ & $B_{\mathrm{C}_{3}}^{\mathrm{CO}}$ \\
\hline Value & 0.68 & 8.86 & 4.60 & 1.56 & 7.10 & 4.20 \\
\hline
\end{tabular}

$$
\begin{aligned}
& \xi=1-x_{\mathrm{H}_{2}}\left\{\frac{1}{9}\left[1-\sqrt{\frac{\exp \left(-\frac{90.64 \times 10^{3}}{K}\right)}{0.68 \times 10^{-2}} \frac{T-T_{0}}{\beta}}\right]^{3}+\frac{2}{9}\left[1-\frac{\exp \left(-\frac{83.6 \times 10^{3}}{R T}\right)}{8.68 \times 10^{-2}} \frac{T-T_{0}}{\beta}\right]^{3}+\frac{6}{9}\left[1-\frac{\exp \left(-\frac{171.80 \times 10^{3}}{R T}\right)}{4.60 \times 10^{-2}} \frac{T-T_{0}}{\beta}\right]^{3}\right\}
\end{aligned}
$$

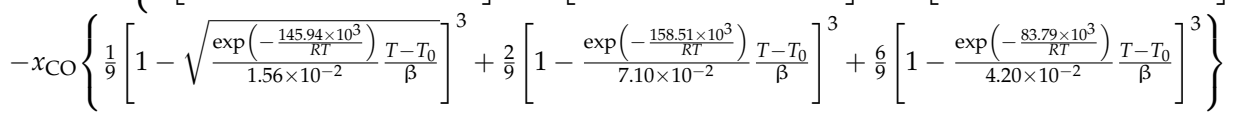

Here, $x_{\mathrm{H}_{2}}$ and $x_{\mathrm{CO}}$ are the mole fractions of $\mathrm{H}_{2}$ and $\mathrm{CO}$, respectively, \%; $T$ is the temperature at time $t$, $\mathrm{K} ; T_{0}$ is the initial temperature, $\mathrm{K}$; and $\beta$ is the heating rate, $\mathrm{K} / \mathrm{min}$.

Figures 16 and 17 show the calculated results and the experimental data of the non-isothermal reduction of HCVTM pellets by gas mixtures under different heating rates and gas compositions. From these data, the correlation coefficient was extracted, and all of the values were greater than 0.99 . This result reveals that the kinetic model obtained based on the unreacted core model with multiple reaction interfaces can be effectively and properly used to describe the non-isothermal reduction of HCVTM pellets by gas mixtures. 

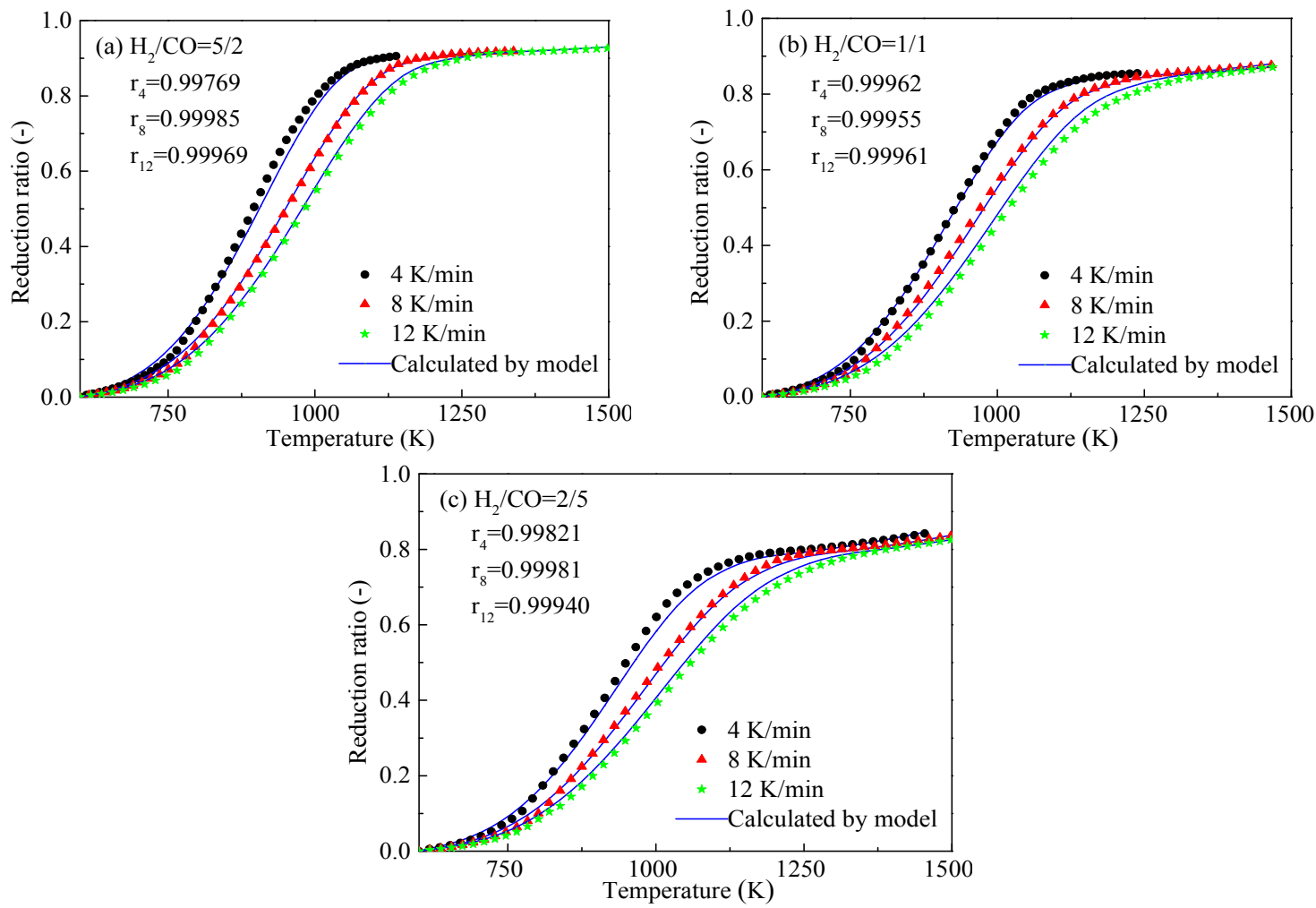

Figure 16. Comparison between the experimental and calculated non-isothermal reduction ratio with different heating rates (a) $\mathrm{H}_{2} / \mathrm{CO}=5 / 2 ;(\mathbf{b}) \mathrm{H}_{2} / \mathrm{CO}=1 / 1 ;$ (c) $\mathrm{H}_{2} / \mathrm{CO}=2 / 5$.
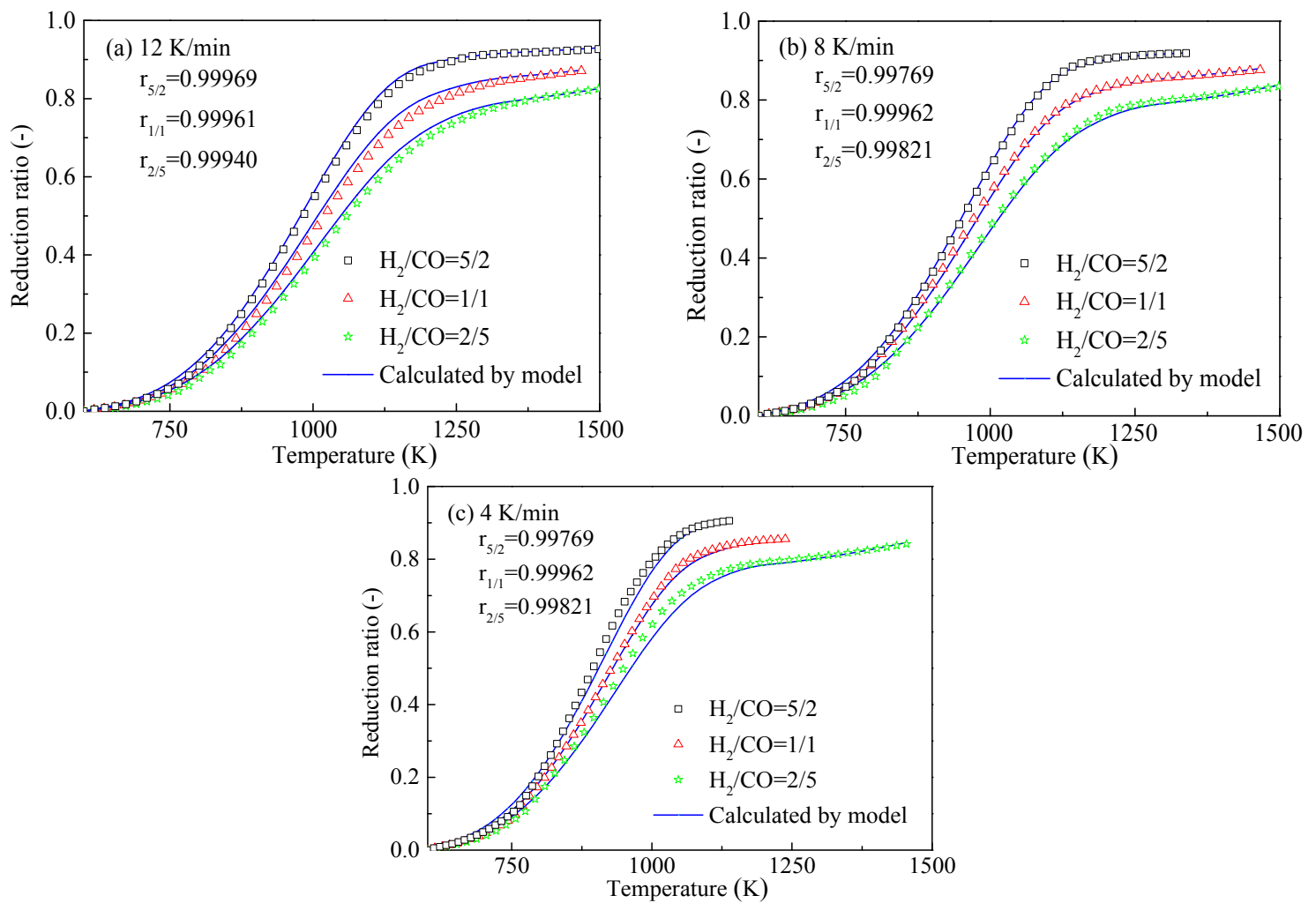

Figure 17. Comparison between the experimental and calculated non-isothermal reduction ratio with different gas compositions (a) $12 \mathrm{~K} / \mathrm{min}$; (b) $8 \mathrm{~K} / \mathrm{min}$; (c) $4 \mathrm{~K} / \mathrm{min}$. 


\subsection{Melting Separation of the Metallized HCVTM Pellets}

The metallized HCVTM pellets with a reduction ratio of approximately $92 \%$ obtained at $1373 \mathrm{~K}$ with a heating rate of $8 \mathrm{~K} / \mathrm{min}$ were applied for the melting separation. The chemical composition of the metallized HCVTM pellets is listed in Table 5 . The temperature and time for the melting separation was controlled at $1923 \mathrm{~K}$ for $40 \mathrm{~min}$. The patterns of the products, including the iron and separation slag, are shown in Figure 18. After the melting separation process was complete, the iron and slag were successfully separated, and the iron containing $\mathrm{V}$ and $\mathrm{Cr}$ with a relatively large density fell to the bottom of the crucible, while the light Ti-rich slag floated on top.

Table 5. Chemical composition of the metallized HCVTM pellet (wt \%).

\begin{tabular}{ccccccccc}
\hline $\mathrm{TFe}$ & $\mathrm{MFe}$ & $\mathrm{TiO}_{2}$ & $\mathrm{~V}_{\mathbf{2}} \mathrm{O}_{5}$ & $\mathrm{Cr}_{2} \mathrm{O}_{3}$ & $\mathrm{Al}_{2} \mathrm{O}_{3}$ & $\mathrm{SiO}_{2}$ & $\mathrm{MgO}$ & $\mathrm{CaO}$ \\
\hline 76.64 & 70.01 & 9.241 & 1.334 & 0.899 & 4.26 & 3.16 & 1.51 & 0.34 \\
\hline
\end{tabular}

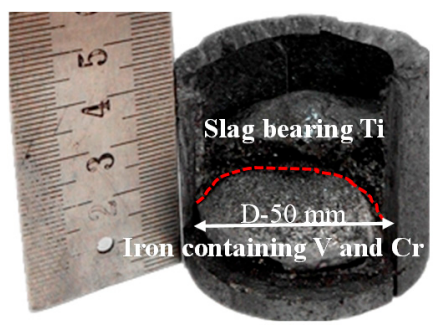

Figure 18. Patterns of melting separation products.

The compositions of the iron and separation slag were analyzed by ICP-OES, and the results are given in Table 6. The elemental recoveries were calculated according to the mass balance as defined in Equations (20) and (21). Through analysis and calculation, the recovery rates of $\mathrm{Fe}, \mathrm{V}$, and $\mathrm{Cr}$ in iron were found to be $99.45 \%, 98.83 \%$, and $95.02 \%$, respectively. The recovery rate of $\mathrm{TiO}_{2}$ in the slag was $95.08 \%$. It is suggested that most of the V and Cr in the HCVTM was concentrated in the iron, and a large proportion of Ti was enriched into the so-called Ti-rich slag. Finally, the efficient separation of Fe, $\mathrm{V}$, and $\mathrm{Cr}$ from Ti was successfully achieved by the novel process of gas-based direct reduction-melting separation. The Ti-rich slag can be used for titanium white production. However, more work is needed to further separate the $\mathrm{V}$ and $\mathrm{Cr}$, such as an alternative method, a separation mechanism, or a metal recovery rate. This process will be the subject of future work.

$$
\begin{gathered}
R_{\mathrm{TiO}_{2}}=\left(W_{2} \times M_{\mathrm{S}}\right) /\left(W_{1} \times M_{\mathrm{P}}\right) \times 100 \% \\
R_{\mathrm{M}}=\left(W_{4} \times M_{\mathrm{I}}\right) /\left(W_{3} \times M_{\mathrm{P}}\right) \times 100 \%
\end{gathered}
$$

Here, $R_{\mathrm{TiO}_{2}}$ and $R_{\mathrm{M}}$ are the recovery values of $\mathrm{TiO}_{2}$ in the slag and the elements $(\mathrm{Fe}, \mathrm{V}$ and $\mathrm{Cr}$ ) in the iron, respectively, \%; $W_{1}$ and $W_{2}$ are the mass fractions of $\mathrm{TiO}_{2}$ in the metallized $\mathrm{HCVTM}$ pellets and slag, respectively, \%; $W_{3}$ and $W_{4}$ are the mass fractions of the elements in the metallized HCVTM pellets and iron, respectively, \%; and $M_{\mathrm{P}}, M_{\mathrm{S}}$, and $M_{\mathrm{I}}$ are the masses of the metallized HCVTM pellets, slag, and iron, respectively, g. 
Table 6. Main chemical compositions of separated iron and slag (wt \%).

\begin{tabular}{cccccccc}
\hline \multicolumn{7}{c}{ Composition of Iron/\% } \\
\hline $\mathrm{TFe}$ & $\mathrm{V}$ & $\mathrm{Cr}$ & $\mathrm{Ti}$ & $\mathrm{Si}$ & $\mathrm{S}$ & $\mathrm{P}$ & - \\
93.87 & 0.91 & 0.72 & 0.56 & 0.034 & 0.027 & 0.041 & - \\
\hline \multicolumn{7}{c}{ Composition of Slag/\% } \\
\hline $\mathrm{TFe}$ & $\mathrm{V}$ & $\mathrm{Cr}$ & $\mathrm{TiO}_{2}$ & $\mathrm{CaO}$ & $\mathrm{SiO}_{2}$ & $\mathrm{MgO}$ & $\mathrm{Al}_{2} \mathrm{O}_{3}$ \\
1.82 & 0.038 & 0.133 & 38.21 & 21.30 & 13.45 & 6.55 & 18.48 \\
\hline
\end{tabular}

\section{Conclusions}

(1) With the increase of the heating rate, the plot of the reduction ratio shifted to the right. The HCVTM pellets reached nearly the same reduction ratio under a given reducing gas composition, although the heating rates were different. Under the same heating rate, the gas mixture with more $\mathrm{H}_{2}$ was conducive for obtaining a higher reduction ratio.

(2) The phase transformations of the HCVTM pellets during the non-isothermal reduction by the gas mixtures were ordered as follows: $\mathrm{Fe}_{2} \mathrm{O}_{3} \rightarrow \mathrm{Fe}_{3} \mathrm{O}_{4} \rightarrow \mathrm{FeO} \rightarrow \mathrm{Fe} ; \mathrm{Fe}_{9} \mathrm{TiO}_{15}+\mathrm{Fe}_{2} \mathrm{Ti}_{3} \mathrm{O}_{9} \rightarrow$ $\mathrm{Fe}_{2.75} \mathrm{Ti}_{0.25} \mathrm{O}_{4} \rightarrow \mathrm{FeTiO}_{3} \rightarrow \mathrm{TiO}_{2} ; \mathrm{V}_{1.7} \mathrm{Cr}_{0.3} \mathrm{O}_{3} \rightarrow \mathrm{V}_{2} \mathrm{O}_{3} \rightarrow \mathrm{Fe}_{2} \mathrm{VO}_{4} ; \mathrm{Fe}_{1.2} \mathrm{Cr}_{0.8} \mathrm{O}_{3} \rightarrow \mathrm{Cr}_{2} \mathrm{O}_{3} \rightarrow$ $\mathrm{FeCr}_{2} \mathrm{O}_{4}$.

(3) Based on the unreacted core model with multiple reaction interfaces, the kinetic model for the non-isothermal reduction of the HCVTM pellets by the gas mixtures was established as follows:

$$
\begin{aligned}
\xi & =1-x_{\mathrm{H}_{2}}\left\{\frac{1}{9}\left[1-\sqrt{\frac{\exp \left(-\frac{90.64 \times 10^{3}}{R T}\right)}{0.68 \times 10^{-2}} \frac{T-T_{0}}{\beta}}\right]^{3}+\frac{2}{9}\left[1-\frac{\exp \left(-\frac{83.68 \times 10^{3}}{R T}\right)}{8.68 \times 10^{-2}} \frac{T-T_{0}}{\beta}\right]^{3}+\frac{6}{9}\left[1-\frac{\exp \left(-\frac{171.80 \times 10^{3}}{R T}\right)}{4.60 \times 10^{-2}} \frac{T-T_{0}}{\beta}\right]^{3}\right\} \\
& -x_{\mathrm{CO}}\left\{\frac{1}{9}\left[1-\sqrt{\frac{\exp \left(-\frac{145.94 \times 10^{3}}{R T}\right)}{1.56 \times 10^{-2}} \frac{T-T_{0}}{\beta}}\right]^{3}+\frac{2}{9}\left[1-\frac{\exp \left(-\frac{158.51 \times 10^{3}}{R T}\right)}{7.10 \times 10^{-2}} \frac{T-T_{0}}{\beta}\right]^{3}+\frac{6}{9}\left[1-\frac{\exp \left(-\frac{83.79 \times 10^{3}}{R T}\right)}{4.20 \times 10^{-2}} \frac{T-T_{0}}{\beta}\right]^{3}\right\}
\end{aligned}
$$

where $x_{\mathrm{H}_{2}}$ and $x_{\mathrm{CO}}$ are the mole fractions in the gas mixtures, respectively, $\%$; $T$ is the temperature at time $t, \mathrm{~K} ; T_{0}$ is the initial temperature, $\mathrm{K}$; and $\beta$ is the heating rate, $\mathrm{K} / \mathrm{min}$. The correlation coefficients were all greater than 0.99 , revealing that the kinetic model could be properly used to describe the non-isothermal reduction of HCVTM pellets by gas mixtures.

(4) Through the melting separation of the metallized HCVTM pellets, the iron containing $\mathrm{V}$ and $\mathrm{Cr}$ along with the Ti-rich slag was obtained. The mass fraction and recovery rates of $\mathrm{Fe}, \mathrm{V}$, and $\mathrm{Cr}$ in iron were $93.87 \%$ and $99.45 \%, 0.91 \%$ and $98.83 \%$, and $0.72 \%$ and $95.02 \%$, respectively. The mass fraction and recovery rate of the $\mathrm{TiO}_{2}$ in the slag were $38.12 \%$ and $95.08 \%$, respectively.

(5) The gas-based direct reduction process is a really promising technology for the disposal of HCVTM. It has low carbon emission and is environment-friendly. Furthermore, the recoveries of valuable elements including $\mathrm{Fe}, \mathrm{V}, \mathrm{Cr}$, and Ti could be improved significantly through the novel process. The subsequent assessment of production cost and other things should be considered comprehensively in future research.

Acknowledgments: The authors are especially grateful to the National Natural Science Foundation of China (Grant No. 51574067).

Author Contributions: Jue Tang, Man-Sheng Chu, Zi-Wei Ying conceived and designed the experiments; Jue Tang performed the experiments, analyzed the data, and compiled the text; Feng Li, Cong Feng, and Zheng-Gen Liu supervised the experimental work and reviewed the manuscript.

Conflicts of Interest: The authors declare no conflict of interest. 


\section{References}

1. Hu, M.; Liu, L.; Lv, X.; Bai, C.; Zhang, S. Crystallization Behavior of Perovskite in the Synthesized High-Titanium-Bearing Blast Furnace Slag Using Confocal Scanning Laser Microscope. Metall. Mater. Trans. B 2014, 45, 76-85. [CrossRef]

2. Long, H.; Chun, T.; Wang, P.; Meng, Q.; Di, Z.; Li, J. Grinding Kinetics of Vanadium-Titanium Magnetite Concentrate in a Damp Mill and Its Properties. Metall. Mater. Trans. B 2016, 47, 1765-1772. [CrossRef]

3. Zhang, L.; Zhang, W.; Zhang, J.; Li, G. Oxidation Kinetics and Oxygen Capacity of Ti-Bearing Blast Furnace Slag under Dynamic Oxidation Conditions. Metals 2016, 6, 105. [CrossRef]

4. Zhou, W.; Xie, B.; Tan, W.F.; Diao, J.; Zhang, X.; Li, H.Y. Non-isothermal Crystallization Kinetics of Spinels in Vanadium Slag with High CaO Content. JOM 2016, 68, 2520-2524. [CrossRef]

5. Tuo, X.; Xu, Z.; Teng, Y.; Mu, K. The Geochemical Characteristics of Heavy Metals in Soils in the Panzhihua V-Ti Magnetite Mine and the Pollution Evaluation. Bull. Mineral. Petrol. Geochem. 2007, 26, 127-131.

6. Zhou, Y.; Yang, D.; Xie, Y.; Wang, P. Distribution Characteristics of Heavy Metals in Soils in Panzhihua V-Ti Magnetite Mine and Pollution Evaluation. Southwest China J. Agric. Sci. 2010, 23, 777-781.

7. Chen, S.; Chu, M. Metalizing Reduction and Magnetic Separation of Vanadium Titano-magnetite Based on Hot Briquetting. J. Miner. Metall. Mater. 2014, 21, 225-233. [CrossRef]

8. Sun, H.; Wang, J.; Han, Y.; She, X.; Xue, Q. Reduction Mechanism of Titanomagnetite Concentrate by Hydrogen. Int. J. Miner. Process. 2013, 125, 122-128. [CrossRef]

9. Park, E.; Ostrovski, O. Reduction of Titania-Ferrous Ore by Carbon Monoxide. ISIJ Int. 2003, 43, $1316-1325$. [CrossRef]

10. Tang, J.; Chu, M.; Li, F.; Tang, Y.; Liu, Z.; Xue, X. Reduction Mechanism of High-chromium Vanadium-titanium Magnetite pellets by $\mathrm{H}_{2}-\mathrm{CO}-\mathrm{CO}_{2}$ Gas Mixtures. Int. J. Miner. Metall. Mater. 2015, 22, 562-572. [CrossRef]

11. Park, E.; Lee, S.B.; Ostrovski, O.; Min, D.J.; Rhee, C.H. Reduction of the Mixture of Titanomagnetite Ironsand and Hematite Iron Ore Fines by Carbon Monoxide. ISIJ Int. 2004, 44, 214-216. [CrossRef]

12. Zhou, L.; Tao, D.; Fang, M.; Zeng, F.; Pu, X. Carbothermic Reduction of V-Ti Magnetite Ore. Chin. J. Rare Met. 2009, 33, 406-410.

13. Jiang, T.; Wang, S.; Guo, Y.; Chen, F.; Zheng, F. Effects of Basicity and MgO in Slag on the Behaviors of Smelting Vanadium Titanomagnetite in the Direct Reduction-Electric Furnace Process. Metals 2016, 6, 107. [CrossRef]

14. Hu, T.; Lv, X.; Bai, C.; Lun, Z.; Qiu, G. Reduction Behavior of Panzhihua Titanomagnetite Concentrates with Coal. Metall. Mater. Trans. B. 2013, 44, 252-260. [CrossRef]

15. Cheng, G.; Liu, J.; Liu, Z.; Chu, M.; Xue, X. Non-isothermal Reduction Mechanism and Kinetics of High Chromium Vanadium-titanium Magnetite pellets. Ironmak. Steelmak. 2015, 42, 17-26. [CrossRef]

16. Wang, M.; Zhou, S.; Wang, X.; Chen, B.; Yang, H.; Wang, S.; Luo, P. Recovery of Iron from Chromium Vanadium-Bearing Titanomagnetite Concentrate by Direct Reduction. JOM 2016, 68, 2698-2703. [CrossRef]

17. Zhang, P. Basic Technology Study on Gas-based Direct Reduction for Indonesia Vanadium-Titanium Magnetite. Master's Thesis, Northeastern University, Shenyang, China, 2014.

18. Li, Y. Basic Research on Gas-based Reduction of Indonesia Ironsand Oxidized Pellets. Ph.D. Thesis, University of Science and Technology Beijing, Beijing, China, 2015.

19. Zhang, J.; Zheng, C.; Tang, Y.; Chai, F. Reduction of Panzhihua titanium-bearing oxidized pellets by CO-N $\mathrm{N}_{2}-\mathrm{H}_{2}$ gas. J. Cent. South Univ. 2016, 23, 1015-1022. [CrossRef]

20. Park, E.; Ostrovski, O. Reduction of Titania-ferrous Ore by Hydrogen. ISIJ Int. 2004, 44, 999-1005. [CrossRef]

21. Ono, N.H.; Yonezawa, T.; Usui, T. Effect of Water-Gas Shift Reaction on Reduction of Iron Oxide Powder Packed Bed with $\mathrm{H}_{2}$-CO Mixtures. ISIJ Int. 2003, 43, 1502-1511.

22. He, G.; Du, X.; Zhang, K.; Tang, Z.; Lou, T.; Tu, G. Research on the Process of Deep Reduction-smelting Separation of Hongge Ore and the Trend of V, Cr. J. Mater. Metall. 2014, 13, 15-19.

23. Zhao, L.; Wang, L.; Chen, D.; Zhao, H.; Liu, Y.; Qi, T. Behaviors of Vanadium and Chromium in Coal-based Direct Reduction of High-chromium Vanadium-bearing Titanomagnetite Concentrates Followed by Magnetic Separation. Trans. Nonferrous Met. Soc. China 2015, 25, 1325-1331. [CrossRef]

24. Zhou, M.; Yang, S.; Jiang, T.; Xue, X. Influence of MgO in Form of Magnesite on Properties and Mineralogy of High Chromium, Vanadium, Titanium Magnetite Sinters. Ironmak. Steelmak. 2015, 42, 217-225. [CrossRef] 
25. Dang, J.; Chou, K.; Hu, X.; Zhang, G. Reduction Kinetics of Metal Oxides by Hydrogen. Steel Res. Int. 2013, 84, 526-533. [CrossRef]

26. Chou, K. A Kinetic Model for Oxidation of Si-Al-O-N Materials. J. Am. Ceram. Soc. 2006, 89, $1568-1576$. [CrossRef]

(c)

(c) 2017 by the authors. Licensee MDPI, Basel, Switzerland. This article is an open access article distributed under the terms and conditions of the Creative Commons Attribution (CC BY) license (http:/ / creativecommons.org/licenses/by/4.0/). 